\title{
El papel de la membrana mitocondrial externa en el control del metabolismo energético celular
}

\author{
Viktor V. Lemeshko \\ Escuela de Física, Facultad de Ciencias, Universidad Nacional de Colombia, sede Medellín, Colombia \\ Artículo de posesión para el ingreso como miembro correspondiente a la \\ Academia Colombiana de Ciencias Exactas, Físicas y Naturales el 23 de noviembre de 2017
}

\begin{abstract}
Resumen
Hasta $95 \%$ de la energía en las células eucariotas se produce en las mitocondrias, las cuales se componen de dos membranas, la interna y la externa. La principal función de la membrana interna es la fosforilación oxidativa. El trifosfato de adenosina (adenosine triphosphate, ATP) y el fosfato de creatina, producidos en las mitocondrias, se transfieren al citosol atravesando la membrana mitocondrial externa, básicamente a través de las porinas (voltagedependent anion cannel, VDAC). Dado que los mecanismos de generación del potencial eléctrico en esta membrana se desconocen, generalmente se asume que la compuerta eléctrica de los VDAC siempre está abierta. Sin embargo, el potencial de la membrana mitocondrial externa puede generarse de manera dependiente del metabolismo energético celular mediante diversos mecanismos. La generación de dicho potencial mediante los complejos VDAC-hexocinasa en las células cancerígenas, o la oxidación directa del NADH citosólico en las mitocondrias de la levadura Saccharomyces cerevisiae permiten explicar los efectos de Crabtree y Warburg como una supresión eléctrica de las mitocondrias. Según el modelo desarrollado, la prevención de la formación de los complejos VDAC-hexocinasa por acción de algunos factores podría causar efectos anti-Warburg y anticancerígenos. Además, este potencial positivo generado por los complejos VDAC-creatina-cinasa podría proteger las mitocondrias de los cardiomiocitos y de otras células frente a los niveles tóxicos de calcio en el citosol. Los mecanismos propuestos de generación del potencial de la membrana dependiente del metabolismo energético celular, sugieren que las propiedades eléctricas del VDAC tienen un papel importante en varios procesos fisiológicos y patofisiológicos. (C) 2018. Acad. Colomb. Cienc. Ex. Fis. Nat.
\end{abstract}

Palabras clave: Membrana externa mitocondrial; VDAC; Potencial de membrana; Levadura; Cáncer; Corazón.

The mitochondrial outer membrane in the control of cell energy metabolism

\begin{abstract}
Up to $95 \%$ of the energy in the eukaryotic cells is produced in the mitochondria, which are composed of two membranes, internal and external. The main function of the inner membrane is the oxidative phosphorylation. ATP and/or phosphocreatine produced in mitochondria are transferred to the cytosol across the mitochondrial outer membrane, mainly through the porins (voltage-dependent anion channel, VDAC). As the mechanisms of generation of the electrical potential on this membrane are not known, it is generally assumed that the VDAC electric gate is always open. However, the outer membrane potential (OMP) of mitochondria may be generated by various mechanisms in a manner dependent on the cell energy metabolism. OMP generation by the VDAChexokinase complexes in cancer cells, or by the direct oxidation of cytosolic NADH in the mitochondria of the yeast Saccharomyces cerevisiae, may explain the Crabtree and Warburg effects as an electrical suppression of mitochondria. According to the model developed, the prevention of the formation of the VDAC-hexokinase complexes may result in anti-Warburg and anti-cancer effects. In addition, the generation of the positive OMP by the VDAC-creatine kinase complexes could protect mitochondria in cardiomyocytes and other cells against toxic levels of cytosolic calcium. The mechanisms proposed for OMP generation dependent on the cell energy metabolism suggest that the VDAC electrical properties play an important role in various physiological and pathophysiological processes. (C) 2018. Acad. Colomb. Cienc. Ex. Fis. Nat.
\end{abstract}

Key words: Mitochondrial outer membrane; VDAC; Membrane potential; Yeast; Cancer; Heart.

Correspondencia:

Viktor V. Lemeshko, vvasilie@unal.edu.co, Recibido: 14 de noviembre de 2017, Aceptado: 5 de febrero de 2018, Editor: Luis Fernando García 


\section{Introducción}

Las mitocondrias, organelas intracelulares formadas por dos membranas, desempeñan un papel fundamental en el metabolismo energético celular. El ATP se sintetiza en la matriz mitocondrial mediante el proceso de la fosforilación oxidativa en la membrana mitocondrial interna. En las mitocondrias de los cardiomiocitos, en las neuronas, en las células musculares y en otras, también se sintetiza el fosfato de creatina (CrP) a partir del ATP y de la creatina (Cr). Para suministrar la energía al citosol, el ATP y el CrP producidos en las mitocondrias atraviesan la membrana mitocondrial externa en su forma aniónica. En varias demostraciones experimentales se ha visto cómo la membrana externa restringe significativamente el flujo entre las mitocondrias y el citosol de estos y otros metabolitos cargados (Vander Heiden, et al., 2000; Lemasters \& Holmuhamedov, 2006; Rostovtseva \& Bezrukov, 2012; Simson, et al., 2016).

La mayor parte de las proteínas de la membrana externa corresponde a las porinas de tipo VDAC (Mannella, 1982), a través de las cuales atraviesan los metabolitos cargados (Colombini, 1979, 2016). Se ha demostrado que el VDAC, con una compuerta sensible al voltaje, cambia su permeabilidad a los aniones en una forma dependiente del potencial eléctrico de la membrana (Colombini, et al., 1996; Rostovtseva \& Colombini, 1997; Colombini \& Mannella, 2012). Por ejemplo, el VDAC se cierra casi completamente para el ATP, con un potencial de membrana de unos $40 \mathrm{mV}$ (positivo o negativo), aunque sigue siendo permeable a los cationes (Benz, et al., 1990; Colombini, et al., 1996; Hodge \& Colombini, 1997).

Sin embargo, varios autores han descartado la posibilidad del control eléctrico del metabolismo energético mitocondrial y celular a nivel de la membrana externa (Benz, et al., 1990; Lemasters \& Holmuhamedov, 2006). Tampoco se han propuestos otros mecanismos para explicar la generación del potencial de la membrana externa, excepto el equilibrio de Donnan (Liu \& Colombini, 1992).

En la actualidad el concepto más aceptado para la regulación de la permeabilidad de la membrana externa es el "taponamiento" molecular de los VDAC, especialmente con la tubulina y otras proteínas mitocondriales o citosólicas (Liu \& Colombini, 1992; Kmita, et al., 2003; Rostovtseva \& Bezrukov, 2012; Rostovtseva, et al., 2015). En el más reciente ejemplo, hasta $98 \%$ de los VDAC en la membrana externa de los cardiomiocitos podría verse taponado por la tubulina y el retículo sarcoplasmático muy cercano a las mitocondrias (Simson, et al., 2016). Sin embargo, los datos experimentales obtenidos en el estudio de Simson, et al. (2016) no descartan que el "taponamiento" solo de una parte de los VDAC favorezca la generación del potencial de la membrana externa y la modulación eléctrica de su permeabilidad frente a varios metabolitos cargados de una manera dependiente del metabolismo energético (Lemeshko, 2014, 2016, 2017a), lo cual también facilita la unión dependiente del potencial de la tubulina con el VDAC (Rostovtseva \& Bezrukov, 2012; Rostovtseva, et al., 2017).
Por otro lado, se ha reportado un potencial eléctrico de hasta $-43 \mathrm{mV}$ relacionado con la membrana externa en células vivas (Porcelli, et al., 2005). Según el análisis teórico (Lemeshko, 2006), se puede suponer que el potencial superficial de la membrana interna de las mitocondrias energizadas pudo haber interferido significativamente en los resultados reportados.

Como alternativa a la regulación de la permeabilidad de la membrana externa mediante el "taponamiento" molecular de los VDAC, se han propuesto varios mecanismos de generación del potencial de la membrana externa (Lemeshko, 2002, 2006, 2014-2017b).

En este estudio se proponen varios mecanismos de generación del potencial de la membrana externa con base en las evaluaciones termodinámicas en los modelos computacionales desarrollados. Se halló que para algunas condiciones fisiológicas, el potencial de la membrana externa puede alcanzar niveles suficientemente elevados para generar el cierre eléctrico de los VDAC en la membrana externa. Se describen dos tipos de mecanismos de generación del potencial: mediante la difusión simple de los metabolitos negativamente cargados a través de la membrana externa, y la transferencia activa del grupo fosforilo a través de esta o de las dos membranas mitocondriales. Asimismo, se evidencia el posible papel fisiológico y patofisiológico del potencial de la membrana externa, lo cual explicaría, por ejemplo, el mecanismo de los efectos de Crabtree y Warburg, y la protección de las células frente a la muerte debida a niveles tóxicos de calcio.

\section{Generación del potencial de la membrana mitocondrial externa mediante la diferencia de su permeabilidad frente a varios metabolitos cargados}

Generación del potencial de la membrana externa mitocondrial mediante la circulación de varios compuestos fosforilados. Las primeras evaluaciones termodinámicas de la generación del potencial de la membrana externa mediante la circulación de metabolitos cargados, con distintos grados de permeabilidad, se hicieron para el modelo con flujos estacionarios del $\mathrm{CrP}$, del fosfato inorgánico y de la creatina $(\mathrm{Cr})$, sin contar con la posible contribución del potencial del equilibrio de Donnan, o contando con ella (Lemeshko \& Lemeshko, 2000). Se ha demostrado que la magnitud del potencial de la membrana externa calculado, con valores de hasta $-5 \mathrm{mV}$ (sin la contribución adicional del potencial de Donnan) y de $-10 \mathrm{mV}$ (con la contribución adicional del potencial de Donnan), depende de la intensidad del flujo metabólico.

En el caso más general (Lemeshko, 2017a), que incluye también la circulación de otros compuestos fosforilados, como el ATP, el adenosín difosfato (ADP) y el adenosín monofosfato (AMP), se puede desarrollar un modelo computacional más complejo que tenga en cuenta las características cinéticas de todas las enzimas y transportadores involucrados en el proceso estacionario, las 
características volt-ampéricas de los VDAC en la membrana externa y las concentraciones de varios metabolitos, aplicando la ecuación de Goldman para cada flujo metabólico a través de la membrana externa. En general, el valor y el signo del potencial final de la membrana externa debe ser el resultado de la superposición de los potenciales eléctricos generados mediante distintos mecanismos en los cuales el VDAC y la membrana externa representan los elementos cruciales en el control del metabolismo energético celular.

Los metabolitos activos de reacciones de reducciónoxidación (redox) de carga negativa, también pueden atravesar la membrana externa y entregar electrones directamente a la cadena respiratoria desde el espacio entre las membranas mitocondriales. En varios casos particulares, como las mitocondrias de plantas (Earnshaw, 1975) y levaduras (Ohnishi, et al., 1966; Rigoulet, et al., 2004), los nucleótidos reducidos de piridina, el NADH o el NADPH producidos en el citosol, la oxidación se da por la vía externa mitocondrial atravesando la membrana.

Modelo de generación del potencial de la membrana mitocondrial externa mediante la circulación de los nucleótidos de piridina, $\mathrm{NADH}$ y $\mathrm{NAD}+$ a través de la membrana. En la levadura $S$. cerevisiae, el NADH que se produce en exceso en el citosol se oxida en la superficie de la membrana interna por acción de la deshidrogenasa externa $\left(\mathrm{DH}_{\mathrm{e}}\right)$, y entrega electrones a la cadena respiratoria (Luttik, et al., 1998; Bakker, et al., 2001). El NAD ${ }^{+}$que se acumula en el espacio entre las membranas mitocondriales vuelve al citosol atravesando la membrana externa para recuperar el NADH. De esta manera, la circulación de los nucleótidos de piridina (Figura 1A) con distintas cargas netas, NADH(2-) y $\mathrm{NAD}^{+}(1-)$, puede llevar a la generación del potencial de la membrana externa (Lemeshko, 2017b). Suponiendo, con base en algunos datos indirectos (Rostovtseva, et al., 2002; Lemeshko, 2017b), que la permeabilidad del VDAC para el $\mathrm{NADH}(2-)$ es más alta que para el $\mathrm{NAD}^{+}(1-)$, el potencial de la membrana externa calculado es negativo (Lemeshko, 2017b). Se sabe, asimismo, que la actividad de la $\mathrm{DH}_{\mathrm{e}}$ se incrementa significativamente con los iones de calcio (Earnshaw, 1975) (Figura 1A).

Sin embargo, la generación del potencial de la membrana externa en las mitocondrias de levaduras nunca se ha demostrado experimentalmente. Además, las restricciones de la permeabilidad observadas en la membrana externa para los metabolitos cargados en estas células, se han explicado por el "taponamiento" de los VDAC con las proteínas citosólicas (Kmita, et al., 2003). Las evaluaciones termodinámicas del potencial de la membrana externa que podría generarse con la circulación del NADH(2-) y el $\mathrm{NAD}^{+}(1-)$ a través de la membrana externa, demuestran que, según el modelo propuesto, la magnitud de dicho potencial, (Figura 1A) puede alcanzar niveles suficientes para el cierre eléctrico del VDAC (Lemeshko, 2017b).

Para mostrar el principio de generación del potencial de la membrana externa mediante la oxidación directa del $\mathrm{NADH}$ externo en las mitocondrias, se describió el proceso estacionario (Figura 1A) con un modelo computacional. La actividad de la $\mathrm{DH}_{\mathrm{e}}$, que cataliza la reacción irreversible de la oxidación del NADH, se expresó con la ecuación:

$$
v=\frac{v_{m} \cdot[N A D H]_{S}}{K_{m, N A D H}+[N A D H]_{S}}
$$

donde $v_{\mathrm{m}}$ es la actividad máxima de la $\mathrm{DH}_{\mathrm{e}}$ de la membrana interna; $[\mathrm{NADH}]_{\mathrm{s}}$ es la concentración del NADH en el espacio entre las membranas mitocondriales; $K_{\mathrm{m}, \mathrm{NADH}}$ es la constante de Michaelis-Menten, correspondiente a $50 \mu \mathrm{M}$ NADH (Rigoulet, et al., 2004). Las velocidades $v_{\mathrm{m}} \mathrm{y} v$, como también los flujos metabólicos de NADH y $\mathrm{NAD}^{+}$a través de la membrana externa, se presentan en unidades arbitrarias relativas.

El flujo de NADH(2-) a través de la membrana externa $\left(J_{\mathrm{NH}}\right)$ se describió con la ecuación de Goldman:

$$
J_{N H}=P_{N H} \cdot \frac{P M E \cdot 2 F}{R T} \cdot \frac{[N A D H]_{c}-[N A D H]_{s} \cdot \exp \left(\frac{-P M E \cdot 2 F}{R T}\right)}{1-\exp \left(\frac{-P M E \cdot 2 F}{R T}\right)}
$$

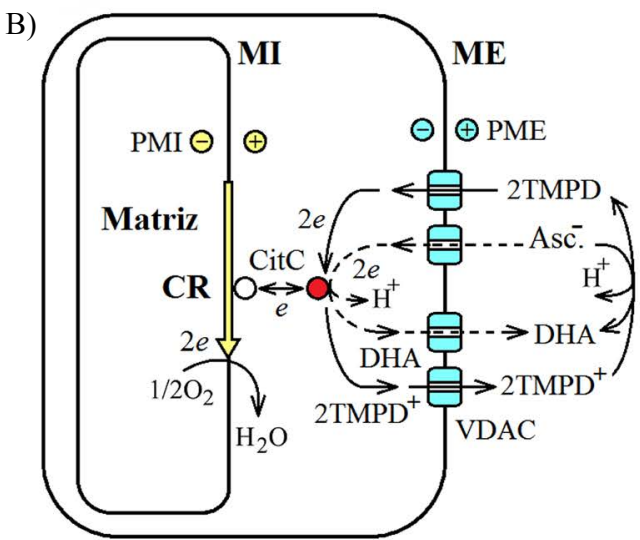

Figura 1. A. Oxidación del NADH en mitocondrias de levaduras y de plantas. B. Oxidación del ascorbato en mitocondrias intactas. MI: membrana interna; ME: membrana externa; $\mathrm{CR}$ : cadena respiratoria; $\mathrm{DH}_{\mathrm{e}}$ : $\mathrm{NADH}$ deshidrogenasa externa de la membrana interna; CitC: citocromo C; Asc'.: ascorbato; DHA: dehidroascorbato; TMPD: N,N,N'N'-tetrametil p-fenilendiamina 
Aquí, $P_{\mathrm{NH}}$ es la permeabilidad de la membrana externa al NADH(2-) a través de los VDAC; $F$ es la constante de Faraday; $R$ es la constante universal de los gases; $T=298 \mathrm{~K}$ es la temperatura del medio, y $[\mathrm{NADH}]_{\mathrm{c}}$ y $[\mathrm{NADH}]_{\mathrm{s}}$ son las concentraciones de NADH en el citosol y en el espacio entre las membranas mitocondriales, respectivamente.

De la misma manera se puede expresar el flujo de $\mathrm{NAD}^{+}(1-)$ a través de la membrana externa:

$$
J_{N}=P_{N} \cdot \frac{P M E \cdot F}{R T} \cdot \frac{\left[N A D^{+}\right]_{c}-\left[N A D^{+}\right]_{s} \cdot \exp \left(\frac{-P M E \cdot F}{R T}\right)}{1-\exp \left(\frac{-P M E \cdot F}{R T}\right)}
$$

donde $P_{\mathrm{N}}$ es la permeabilidad de la membrana externa al $\mathrm{NAD}^{+}(1-)$ a través de los VDAC, y $\left[\mathrm{NAD}^{+}\right]_{\mathrm{c}}$ y $\left[\mathrm{NAD}^{+}\right]_{\mathrm{s}}$ son las concentraciones de $\mathrm{NAD}^{+}$en el citosol y en el espacio entre las membranas mitocondriales, respectivamente.

La permeabilidad $P_{\mathrm{NH}}$ de la membrana externa al NADH(2-) a través de los VDAC (Figura 1A) en función de su potencial, se describió con la siguiente ecuación (Lemeshko, 2017b):

$$
P_{N H}=0.02+0.98 \cdot \exp -\left(S \cdot k_{N H} \cdot P M E\right)^{2}
$$

donde $S$ es un parámetro de la sensibilidad del VDAC al voltaje tomado a $S=40 \mathrm{~V}^{-1}$. El factor $k_{\mathrm{NH}}$ describe la modulación de la sensibilidad eléctrica del VDAC por su interacción directa con el NADH (Zizi, et al., 1994). Este factor se puede expresar con la ecuación:

$$
k_{N H}=1+\frac{0.25 \cdot[\mathrm{NADH}]_{c}}{K_{d}+[\mathrm{NADH}]_{c}}
$$

Aquí, [NADH] $]_{\mathrm{c}}$ es la concentración del NADH en el citosol, y $K_{\mathrm{d}}$ es igual a $16 \mu \mathrm{M}$ NADH (Zizi, et al., 1994).

La permeabilidad $P_{\mathrm{N}}$ de la membrana externa al NAD ${ }^{+}$ en función del potencial se presenta de la misma manera que la del NADH, para cuyo cálculo se tomó un valor absoluto de la permeabilidad de la membrana externa 6,5 veces menor que para el NADH (Lemeshko, 2017b):

$$
P_{N}=0.003+0.15 \cdot \exp -\left(S \cdot k_{N H} \cdot P M E\right)^{2}
$$

En el estado estacionario, los flujos de NADH y NAD ${ }^{+}$ deben ser iguales a la actividad de la $\mathrm{DH}_{\mathrm{e}}$ de la membrana interna (Figura 1A), es decir:

y

$$
v=J_{N H}
$$

$$
v=-J_{N}
$$

Se debe cumplir también la ecuación de balance de masas:

$$
[N A D H]_{S}+\left[N A D^{+}\right]_{S}=[N A D H]_{C}+\left[N A D^{+}\right]_{C}
$$

donde $[\mathrm{NADH}]_{\mathrm{s}}$ y $\left[\mathrm{NAD}^{+}\right]_{\mathrm{s}}$ corresponden a las concentraciones en el espacio entre las membranas mitocondriales, y $[\mathrm{NADH}]_{\mathrm{c}}$ y $\left[\mathrm{NAD}^{+}\right]_{\mathrm{c}}$ a las concentraciones en el citosol. La ecuación (9) del sistema de ecuaciones (1) a (9) permite definir la concentración del NADH adicionado en ausencia del $\mathrm{NAD}^{+}$adicionado o, también, presentar el $[\mathrm{NADH}]_{\mathrm{c}}$ como si fuera NADH producido por alguna deshidrogenasa extramitocondrial a partir de cierta cantidad del $\mathrm{NAD}^{+}$adicionado a la concentración inicial de $\left[\mathrm{NAD}^{+}\right]_{\mathrm{c}}=1,5 \mathrm{mM}$.
Se supone que el estado estacionario se establece iniciando la actividad de la $\mathrm{DH}_{\mathrm{e}}$ de la membrana interna desde el estado de equilibrio del sistema con las concentraciones de $[\mathrm{NADH}]_{\mathrm{c}}$ y $\left[\mathrm{NAD}^{+}\right]_{\mathrm{c}}$ definidas según la ecuación (9). El sistema de ecuaciones (1) a (9) se resolvió usando el programa Mathcad Professional.

En la Figura 2A se muestran los resultados de las evaluaciones del potencial de la membrana externa generado por la circulación de $\mathrm{NADH}(2-) / \mathrm{NAD}^{+}(1-)$ a través de esta (Figura 1A) para el caso del NADH adicionado a la suspensión de mitocondrias de levadura $S$. cerevisiae $\sin$ adición de $\mathrm{NAD}^{+}$. Dicho potencial está expresado en función de la concentración de $[\mathrm{NADH}]_{\mathrm{c}}$ en el medio exterior y de la actividad máxima de la deshidrogenasa $\mathrm{DH}_{\mathrm{e}}$ de la membrana interna. El potencial de la membrana externa calculado alcanza hasta $-30 \mathrm{mV}$, y según las ecuaciones (4) y (6), su signo negativo se debe a una supuesta mayor permeabilidad del VDAC al NADH(2-) en comparación con el $\mathrm{NAD}^{+}(1-)$ (Lemeshko, 2017b).

Los cálculos demuestran una restricción significativa del flujo metabólico ( $v$ ) (Figura 2D) en el rango de valores relativamente altos de la velocidad máxima de la $\mathrm{DH}_{\mathrm{e}}$. Debe señalarse que el efecto de la restricción en estas condiciones se debe al cierre eléctrico de los VDAC de la membrana externa, porque no se observa restricción a la sensibilidad eléctrica nula del VDAC, $S=0 \mathrm{~V}^{-1}$ (Lemeshko, 2017b).

En experimentos con los esferoplastos permeabilizados de $S$. cerevisiae, se ha visto que la velocidad de oxidación del NADH producido por las deshidrogenasas citosólicas, o por la externa, es mucho más alta que la del NADH adicionado (Avéret, et al., 2002). Es muy importante resaltar que para la producción del NADH por las deshidrogenasas en estos experimentos el medio de incubación contenía 1-2 $\mathrm{mM}$ de $\mathrm{NAD}^{+}$, lo que según las ecuaciones (3), (6) y (9), debería afectar la generación del potencial de la membrana externa y el flujo metabólico a través de esta.

Los cálculos realizados con distintas concentraciones $[\mathrm{NADH}]_{\mathrm{c}}$ del NADH producido en el medio extramitocondrial a partir de $1,5 \mathrm{mM}$ de $\mathrm{NAD}^{+}$en reemplazo de parte del $\mathrm{NAD}^{+}$adicionado, también evidenciaron un mayor flujo metabólico (Figura 2E,a), aunque todavía restringido para el rango de valores relativamente altos de ambos, así como de la actividad máxima de la $\mathrm{DH}_{\mathrm{e}}$ y de la relación $[\mathrm{NADH}]_{\mathrm{c}} /\left[\mathrm{NAD}^{+}\right]_{\mathrm{c}}$ (Figura $2 \mathrm{E}, a$ ). Para este rango, el potencial de la membrana externa generado es de mayor magnitud (Figura 2B, $a$ ).

La restricción metabólica mencionada se debe al cierre eléctrico del VDAC, ya que ésta no se observó esencialmente en el caso de la sensibilidad nula del VDAC al voltaje cuando $\mathrm{S}=0 \mathrm{~V}^{-1}$ (Figura 2E, $b$ ), y los valores calculados del potencial de la membrana externa fueron relativamente bajos (Figura 2B, $b$ ).

Se sabe, asimismo, que la permeabilidad de la membrana externa de las mitocondrias de levaduras puede verse restringida por las interacciones de los VDAC de la 
A)
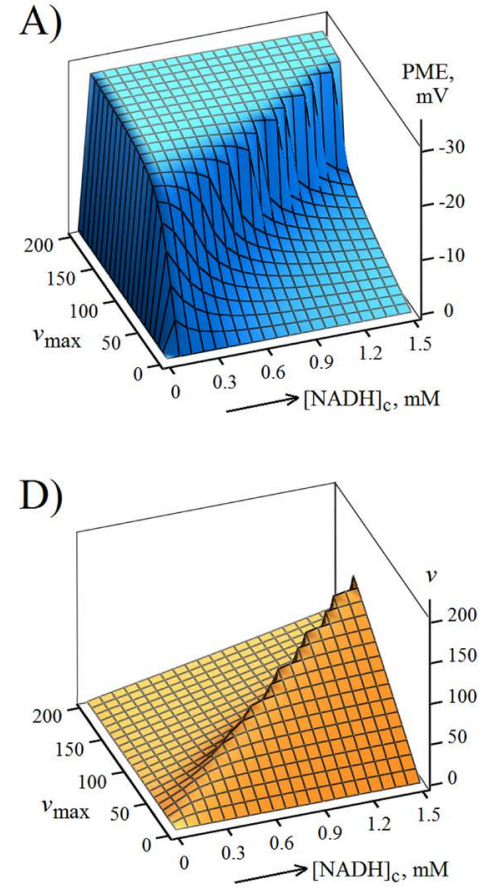

B)

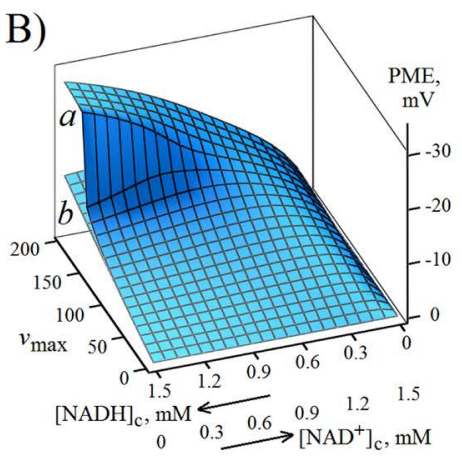

E)

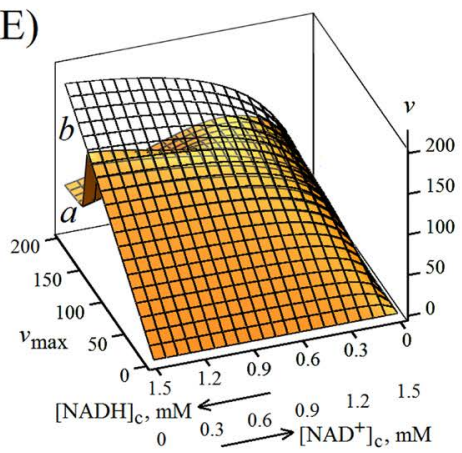

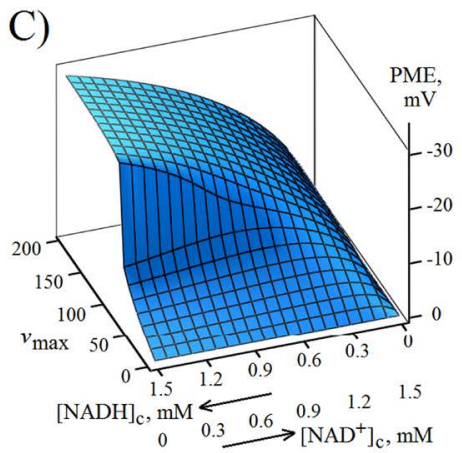

F)

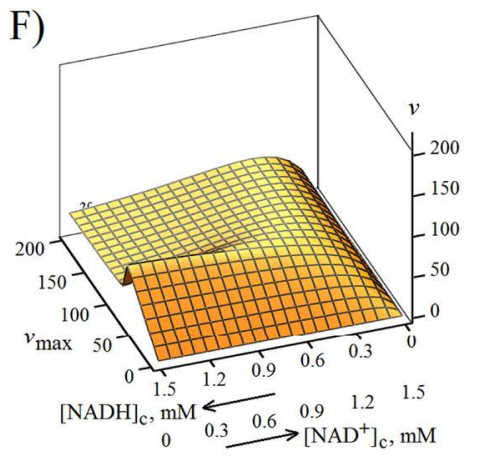

Figura 2. Evaluación del potencial de la membrana externa (A-C) y del flujo metabólico de NADH(2-)/NAD $(1-)$ a través de la membrana externa (D-F) para varias condiciones del modelo (Figura 1A). A,D: en función de la concentración del NADH adicionado, y en ausencia de $\mathrm{NAD}^{+}$; B,C,E,F: en función del NADH producido en la concentración [NADH $]_{\mathrm{c}}$ a partir de una fracción de $1,5 \mathrm{mM}^{\mathrm{N}} \mathrm{Ne} \mathrm{NAD}^{+}$adicionado; A,B $(a), \mathrm{C}, \mathrm{D}, \mathrm{E}(\mathrm{a}), \mathrm{F}: S=40 \mathrm{~V}^{-1} ; \mathrm{B}(b), \mathrm{E}(b)-S=0 \mathrm{~V}^{-1} ; \mathrm{C}, \mathrm{F}:$ knockdown o inhibición de $50 \%$ de los VDAC de la membrana externa, en comparación con $\mathrm{B}(a), \mathrm{E}(a)$.

membrana con las proteínas citosólicas (Kmita, et al., 2003), o por la deficiencia de los VDAC en esta (Avéret, et al., 2002; Kmita, et al., 2003). Para evaluar la influencia del knockdown o de la inhibición en $50 \%$ de los VDAC de la membrana externa, el modelo se analizó con el sistema de ecuaciones (1) a (9), multiplicando la parte derecha de las ecuaciones (4) y (6) por el factor 0,5 (50\% de knockdown). El análisis del modelo con dicho factor evidenció una restricción del flujo metabólico $(v)$ aún mayor (Figura 2, F en comparación con $\mathrm{E}, a$ ) debido a la generación del potencial de la membrana externa en magnitudes altas (Figura 2, $\mathrm{C}$ en comparación con $\mathrm{B}, a$ ).

La deshidrogenasa $\mathrm{DH}_{\mathrm{e}}$ de la membrana interna de las mitocondrias de plantas y levaduras se activa significativamente con el $\mathrm{Ca}^{2+}$ (Earnshaw, 1975). Se ha demostrado que la adición de $3 \mathrm{mM}$ de EGTA dos a tres minutos después de la adición de $1 \mathrm{mM}$ de NADH a la suspensión de mitocondrias de maíz causa una leve inhibición de la respiración, mientras que la adición de $3 \mathrm{mM}$ de EGTA antes del NADH la inhibe por lo menos en 60-70\%.

Estos datos experimentales (Earnshaw, 1975) se pueden explicar con base en el modelo de generación del potencial de la membrana externa por la circulación de NADH(2-)/ $\mathrm{NAD}^{+}(1-)$ a través de la membrana. Con el potencial negativo que se genera durante la oxidación del NADH (Figura 1A), el calcio del medio de incubación es capturado hacia el espacio entre las membranas mitocondriales y se mantiene allí en una concentración elevada, suficiente para mantener una gran actividad de la deshidrogenasa $\mathrm{DH}_{\mathrm{e}}$ de la membrana interna. Pero si el EGTA se agrega primero, la oxidación lenta del NADH generaría un potencial de la membrana externa de poco valor, el cual no es suficiente para mantener el $\mathrm{Ca}^{2+}$ cerca de la $\mathrm{DH}_{\mathrm{e}}$ en la concentración necesaria para la activación de esta enzima.

Lo más importante es que el modelo (Figura 1A) permite explicar también la inhibición de la respiración de la levadura $S$. cerevisiae con concentraciones altas de glucosa como un efecto de la supresión eléctrica del metabolismo mitocondrial en estas células (Lemeshko, 2017b).

Otro fenómeno bien conocido es que el ascorbato no se oxida en mitocondrias intactas, aunque el VDAC en su estado abierto debería ser permeable a este anión orgánico natural dependiendo de su tamaño y carga negativa. La oxidación del ascorbato se activa muy significativamente con el TMPD ${ }^{+}$(Figura 1B). Como hipótesis, se puede suponer que el ascorbato, al oxidarse por acción del citocromo $\mathrm{C}$ en el espacio entre las membranas mitocondriales y producir dehidroascorbato (DHA) neutro, lleva a la generación del potencial negativo de la membrana externa de un modo similar a la oxidación del NADH externo (Figura 1A). Así, la inhibición de la oxidación del ascorbato podría explicarse por el mecanismo de retroalimentación negativa, o sea, por 
la generación de potencial negativo de la membrana externa y el cierre eléctrico del VDAC. En el caso de la presencia adicional de $\mathrm{TMPD}^{+}$, éste es reducido por el ascorbato en el medio exterior y luego circula a través de la membrana externa en sus formas neutra y positiva (Figura 1B), ya que el VDAC eléctricamente cerrado no restringe el paso de los cationes de este tamaño.

\section{Generación del potencial de la membrana mitocondrial externa mediante la transferencia activa del grupo fosforilo a través de las membranas}

Se conocen distintos mecanismos de transferencia del grupo fosforilo a través de la membrana externa mitocondrial (Brdiczka, et al., 2006). Uno de estos es el intercambio de ATP y ADP a través de los sitios de contacto entre las dos membranas mitocondriales formados por el antiportador ATP/ADP (ANT) de la membrana interna y el VDAC de la membrana externa (Figura 3A). Un segundo mecanismo se da por la acción de la enzima hexocinasa $(\mathrm{HK})$, la cual forma un complejo con el VDAC (Figura 3B), o con el dúo ANTVDAC (Figura 3C), y hace la transferencia del grupo fosforilo del ATP mitocondrial a la glucosa del citosol formando la glucosa-6-fosfato (G6P') externa (Lemeshko, 2002, 2014, 2017a). El tercer mecanismo se basa en la participación de la creatina cinasa, la cual forma un complejo con el VDAC sin el ANT (Figura 3D) o con el ANT de la membrana interna (Figura 3E), transfiriendo el grupo fosforilo del ATP mitocondrial a la creatina citosólica, $\mathrm{Cr}$, y produciendo el fosfato de creatina $\left(\mathrm{CrP}^{1-}\right)$, o viceversa (Lemeshko, 2016, 2017a). Las mismas posibilidades existen para otras cinasas.
A)

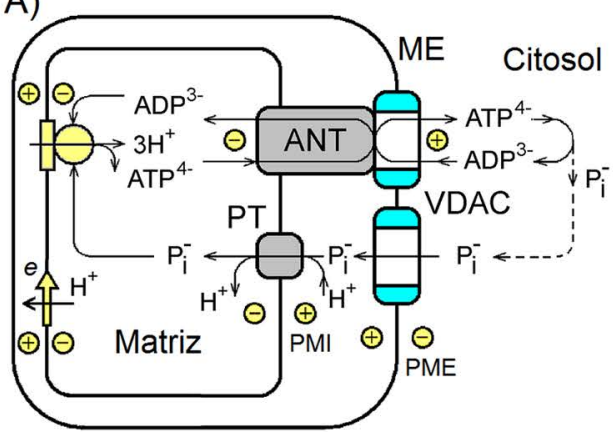

B)

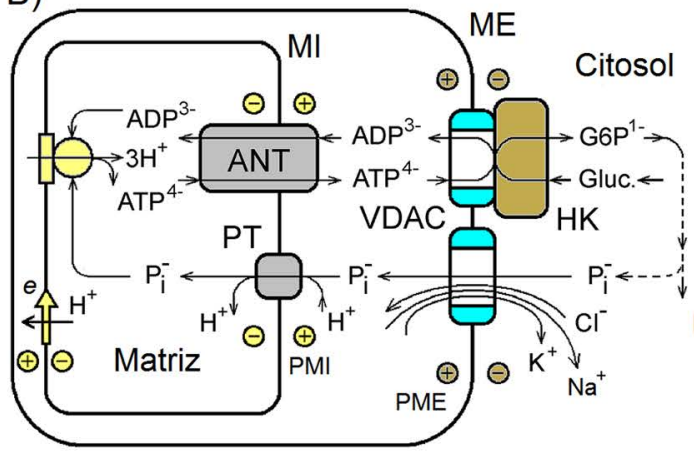

D)

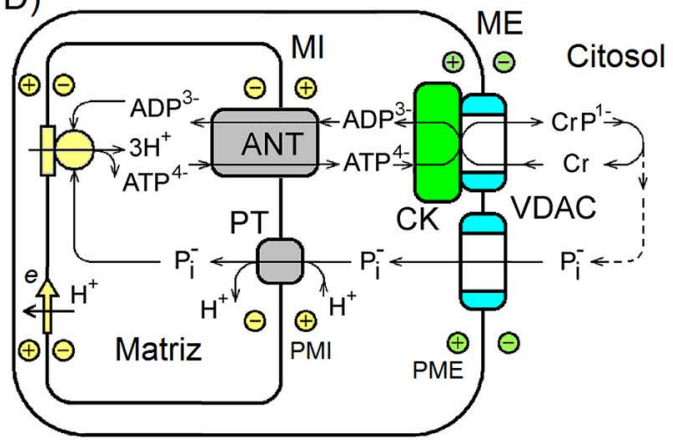

a)

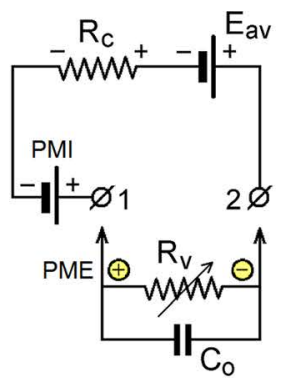

b)

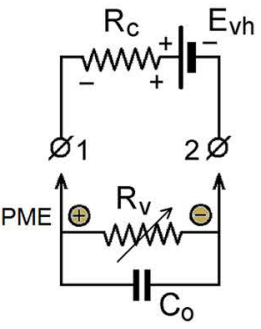

d)

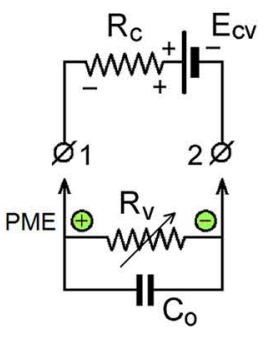

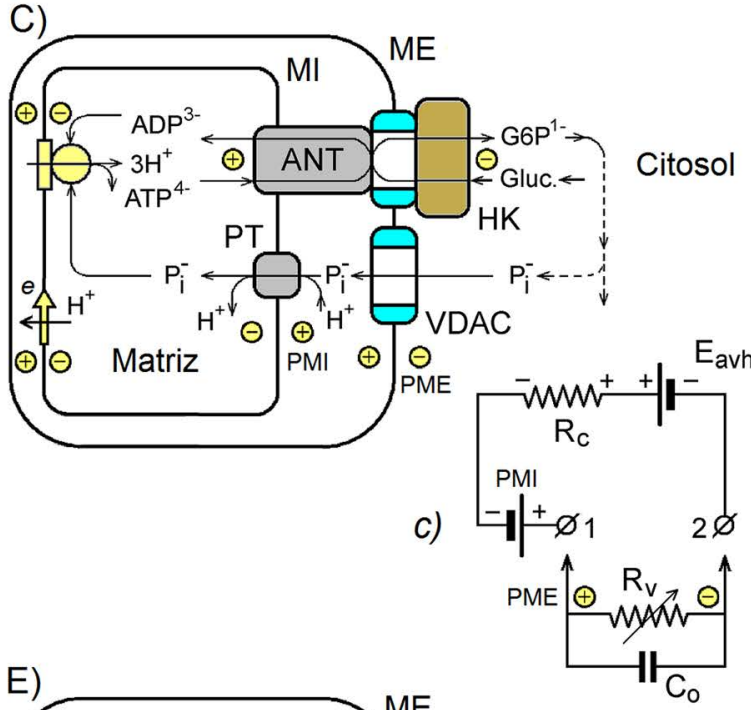

Citosol

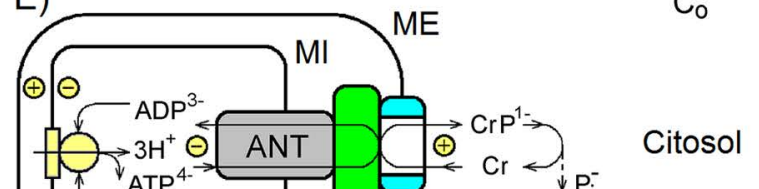

Figura 3. Posibles mecanismos de generación del potencial de la membrana externa mediante la transferencia activa del grupo fosforilo a través de las membranas mitocondriales (A-E), y los respectivos circuitos eléctricos equivalentes ( $a-e)$. A, $a$ : mediante los sitios de contacto entre las membranas mitocondriales de tipo ANT-VDAC; B, $b$ : mediante el complejo VDAC-HK; C, $c$ : mediante los complejos ANT-VDAC$\mathrm{HK}$; D,d: mediante el complejo CK-VDAC; E,e: mediante los complejos ANT-CK-VDAC; MI: membrana interna; ME: membrana externa 
La transferencia del grupo fosforilo al citosol en el estado estacionario del sistema, se acompaña con el regreso del fosfato inorgánico $\left(\mathrm{P}_{i}^{1-}\right)$ desde el citosol a través de los VDAC libres de la membrana externa para recuperar el ATP en la matriz mitocondrial. Los modelos mencionados se pueden presentar con circuitos eléctricos equivalentes (Lemeshko, 2002, 2014, 2016, 2017a, 2017b), como se muestra en la Figura 3, a-e.

Generación del potencial de la membrana externa mediante los complejos VDAC-HK. En las células cancerígenas, una gran cantidad de la hexocinasa (HK) está unida a la membrana externa mitocondrial y forma hasta 300 veces más complejos VDAC-HK que en las mitocondrias de las células normales (Marín-Hernández, et al., 2006; John, et al., 2011), con lo cual se lograría tener acceso preferente al ATP producido por las mitocondrias y facilitar el inicio de la glucólisis. Por otro lado, los complejos VDAC-HK, al transferir grupos fosforilo a través de la membrana externa, deben generar directamente su potencial (Lemeshko, 2002, 2014), el cual, a su vez, podría controlar eléctricamente la permeabilidad de la membrana externa a varios metabolitos cargados.

Se consideró un modelo computacional simplificado para el análisis termodinámico de este mecanismo de generación del potencial de la membrana externa (Figura $3 \mathrm{~B}, b$ ) en cuyo marco la totalidad de los VDAC en dicha membrana se presenta como la suma de varias fracciones: la fracción $N_{\mathrm{vh}}$ de los VDAC que forman complejos con la hexocinasa (VDAC-HK), la fracción $N_{\mathrm{vs}}$ de los VDAC libres sensibles al voltaje, y la fracción $N_{\mathrm{ns}}$ de los VDAC libres que no son sensibles al voltaje.

La fracción $N_{\mathrm{ns}}$ actúa como la fracción de la isoforma VDAC3, poco sensible al voltaje, y puede representar hasta el $10 \%$ de todos los VDAC (Maldonado, et al., 2013). La cantidad total de los VDAC se normaliza a 1:

$$
N_{v h}+N_{v s}+N_{n s}=1
$$

La permeabilidad $P_{\mathrm{vs}}$ de la membrana externa al fosfato inorgánico $\mathrm{P}_{\mathrm{i}}$ a través de la fracción $N_{\mathrm{vs}}$ de los VDAC sensibles al voltaje, se presenta en función del potencial de la membrana externa (Lemeshko, 2014):

$$
P_{v s}=N_{v s} \cdot\left[P_{c}+\left(1-P_{c}\right) \cdot \exp -(S \cdot|P M E|)^{2}\right]
$$

En esta ecuación $S$ es el parámetro de la sensibilidad del VDAC al voltaje, tomado a $S=40 \mathrm{~V}^{-1}$. El parámetro $P_{\mathrm{c}}$ es la permeabilidad de los VDAC eléctricamente cerrados. Para los cálculos en este modelo se tomó un valor de $P_{\mathrm{c}}=0,25$.

La permeabilidad $P_{\mathrm{vh}}$ de la fracción $N_{\mathrm{vh}}$ de los VDAC que forman los complejos VDAC-HK, y la permeabilidad $P_{\text {ns }}$ de la fracción $N_{\text {ns }}$ de los VDAC no sensibles al voltaje se presentan con las ecuaciones (12) y (13), respectivamente:

$$
\begin{aligned}
& P_{v h}=N_{v h} \\
& P_{n s}=N_{n s}
\end{aligned}
$$

Así, las resistencias $R_{\mathrm{c}}$ y $R_{\mathrm{v}}$ en la figura 3, $b$ están dadas por $R_{\mathrm{c}}=1 / P_{\mathrm{vh}}$ y $R_{\mathrm{v}}=1 /\left(P_{\mathrm{vs}}+P_{\mathrm{ns}}\right)$.
El complejo electrogénico VDAC-HK, que transfiere activamente el grupo fosforilo a través de la membrana externa, se puede considerar como una batería biológica, alimentada por la energía libre de Gibbs de la reacción de la hexocinasa (Lemeshko, 2014). El voltaje $E_{\mathrm{vh}}$ generado por esta batería se presenta como:

$$
E_{v h}=-\left(\frac{\Delta G_{h}^{o^{\prime}}}{F}+\frac{R T}{F} \ln \frac{[G 6 P]_{c} \cdot[A D P]_{s}}{[G]_{c} \cdot[A T P]_{s}}\right)
$$

donde $\Delta G_{\mathrm{h}}{ }^{{ }^{\prime}}=-16,7 \mathrm{~kJ} / \mathrm{mol}$ es la energía libre de Gibbs estándar de la reacción de la hexocinasa; $[\mathrm{ATP}]_{\mathrm{S}}$ y $[\mathrm{ADP}]_{\mathrm{s}}$ son las concentraciones del ATP y el ADP en el espacio entre las membranas mitocondriales, respectivamente; $[\mathrm{G}]_{\mathrm{c}}$ y $[\mathrm{G} 6 \mathrm{P}]_{\mathrm{c}}$ son las concentraciones de glucosa y glucosa6-fosfato en el citosol; $F$ es la constante de Faraday; $R$ es la constante universal de los gases, y $T=298 K$ es la temperatura del medio. Para los cálculos, la relación $[\mathrm{G}]_{\mathrm{c}}{ }^{\prime}$ $[\mathrm{G} 6 \mathrm{P}]_{\mathrm{c}}$ se cambia en un rango amplio, de 1 a 100 . Teniendo en cuenta que en condiciones fisiológicas $[\mathrm{G} 6 \mathrm{P}]_{\mathrm{c}}=0,1 \mathrm{mM}$, aproximadamente, este rango corresponde a cambios de concentración de la glucosa de hasta $10 \mathrm{mM}$.

La relación $[\mathrm{ATP}]_{\mathrm{s}} /[\mathrm{ADP}]_{\mathrm{s}}$ se define por la energía libre de Gibbs de la hidrólisis del ATP, $\Delta \mathrm{G}_{\mathrm{a}}$, la cual se mantiene por el proceso de la fosforilación oxidativa en las mitocondrias:

$$
\Delta G_{a}=\Delta G_{a}^{o^{\prime}}+R T \ln \frac{\left[P_{i}^{-1}\right]_{s} \cdot[A D P]_{s}}{[A T P]_{s}}
$$

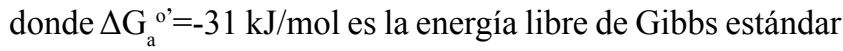
para la reacción de la hidrólisis del ATP. Se sabe que para las células vivas en estado de reposo, $\Delta \mathrm{G}_{\mathrm{a}}$ es igual a- $61 \mathrm{~kJ} / \mathrm{mol}$, aproximadamente (Pinz, et al., 2008). Se consideró que la concentración del fosfato inorgánico para los cálculos era fija: $\left[\mathrm{P}_{\mathrm{i}}^{-1}\right]_{\mathrm{s}}=5 \mathrm{mM}$.

La circulación del grupo fosforilo, promovido por la energía libre de Gibbs de la reacción de la hexocinasa del complejo VDAC-HK, con el regreso del fosfato inorgánico al espacio entre las membranas mitocondriales, se puede presentar como la corriente eléctrica causada por el voltaje $E_{\mathrm{vh}}$. El valor de $E_{\mathrm{vh}}$ depende del estado energético definido por las ecuaciones (14) y (15). Según la ley de $\mathrm{Ohm}$, el potencial de la membrana externa generado se puede presentar como la caída de voltaje sobre la resistencia $R_{\mathrm{v}}$ (Figura 3, $b$ ):

$$
P M E=E_{v h} \cdot \frac{P_{v c}}{P_{v c}+\left(P_{v s}+P_{n s}\right)}
$$

El sistema de ecuaciones (10) a (16) se resolvió para distintas fracciones $N_{\mathrm{vh}}$ de los VDAC que forman complejos VDAC-HK y para distintas concentraciones de la glucosa (de la relación $[\mathrm{G}]_{\mathrm{c}} /[\mathrm{G} 6 \mathrm{P}]_{\mathrm{c}}$ ), suponiendo que el potencial de fosforilación de las mitocondrias era fijo, $\Delta \mathrm{G}_{\mathrm{a}}=-61 \mathrm{~kJ} / \mathrm{mol}$ (ecuación 15).

En este caso simplificado, se considera que en todo el rango de las concentraciones de glucosa (relaciones $[\mathrm{G}]_{\mathrm{c}} /$ $[\mathrm{G} 6 \mathrm{P}]_{\mathrm{c}}$ usadas para los cálculos), la actividad de la hexocinasa 
del complejo VDAC-HK no es un factor limitante para la transferencia del grupo fosforilo a través del complejo. Los cálculos demuestran (Figura 4) un comportamiento del modelo similar al caso en el que se consideraban también las características cinéticas de la HK (Lemeshko, 2014).

En ausencia de los VDAC no sensibles al voltaje, $N_{\mathrm{ns}}=0$, el valor del potencial de la membrana externa calculado según las ecuaciones (10) a (16) depende del porcentaje de los complejos VDAC-HK (del VDAC $\mathrm{HK}_{\mathrm{HK}} \%=N_{\mathrm{vh}} \cdot 100 \%$ ), y alcanza valores de más de $60 \mathrm{mV}$ (Figura 4A). Según el modelo, la generación del potencial debe causar una profunda restricción de la permeabilidad de la membrana externa al fosfato inorgánico (Figura 4C), restringiendo de esta manera todo el flujo metabólico.

En el modelo se evidencia otro fenómeno interesante, un cambio brusco del potencial de la membrana externa y de su permeabilidad en función de la concentración de glucosa (de la relación $[\mathrm{G}]_{\mathrm{c}} /[\mathrm{G} 6 \mathrm{P}]_{\mathrm{c}}$ ) si el porcentaje de los VDAC que forman los complejos VDAC-HK es superior a $3 \%$ $\left(\mathrm{VDAC}_{\mathrm{HK}}>3 \%\right)$ (Figura 4A, C).

Estos cambios del potencial y del flujo metabólico no fueron tan bruscos en presencia de los VDAC no sensibles al voltaje, a $N_{\mathrm{ns}}=0,1(10 \%$ ) (Figura $4 \mathrm{~B}, \mathrm{D})$. Aunque los valores del potencial calculado para este caso son relativamente bajos (Figura 4B), la modulación eléctrica del flujo metabólico a través de la membrana externa puede ser todavía significativa (Figura 4D).

La generación del potencial de la membrana externa también sería posible con la contribución adicional del potencial de la membrana mitocondrial interna, cuando este se aplica a la membrana externa a través del complejo triple ANT-VDACHK (Figura 3C) o, incluso, solamente a través del complejo ANT-VDAC (Figura 3A) (Lemeshko, 2002, 2017a).

En la Figura 5 se comparan los mecanismos más simples de generación del potencial negativo de la membrana externa y del positivo. Según el análisis termodinámico (Figura 2, A-C), es de esperarse la generación del potencial negativo mediante la circulación de los nucleótidos de piridina, $\mathrm{NADH}(2-) / \mathrm{NAD}^{+}(1-)$, a través de la membrana externa (mecanismo del tipo de las levaduras) (Lemeshko, 2017b). El potencial positivo (Figura 4, A,B) debe ser generado directamente por los complejos VDAC-HK (mecanismo del tipo del cáncer) (Lemeshko, 2002, 2014). Con los dos mecanismos cabe esperar un incremento significativo de los valores del potencial de la membrana externa en concentraciones altas de glucosa en el citosol, con la
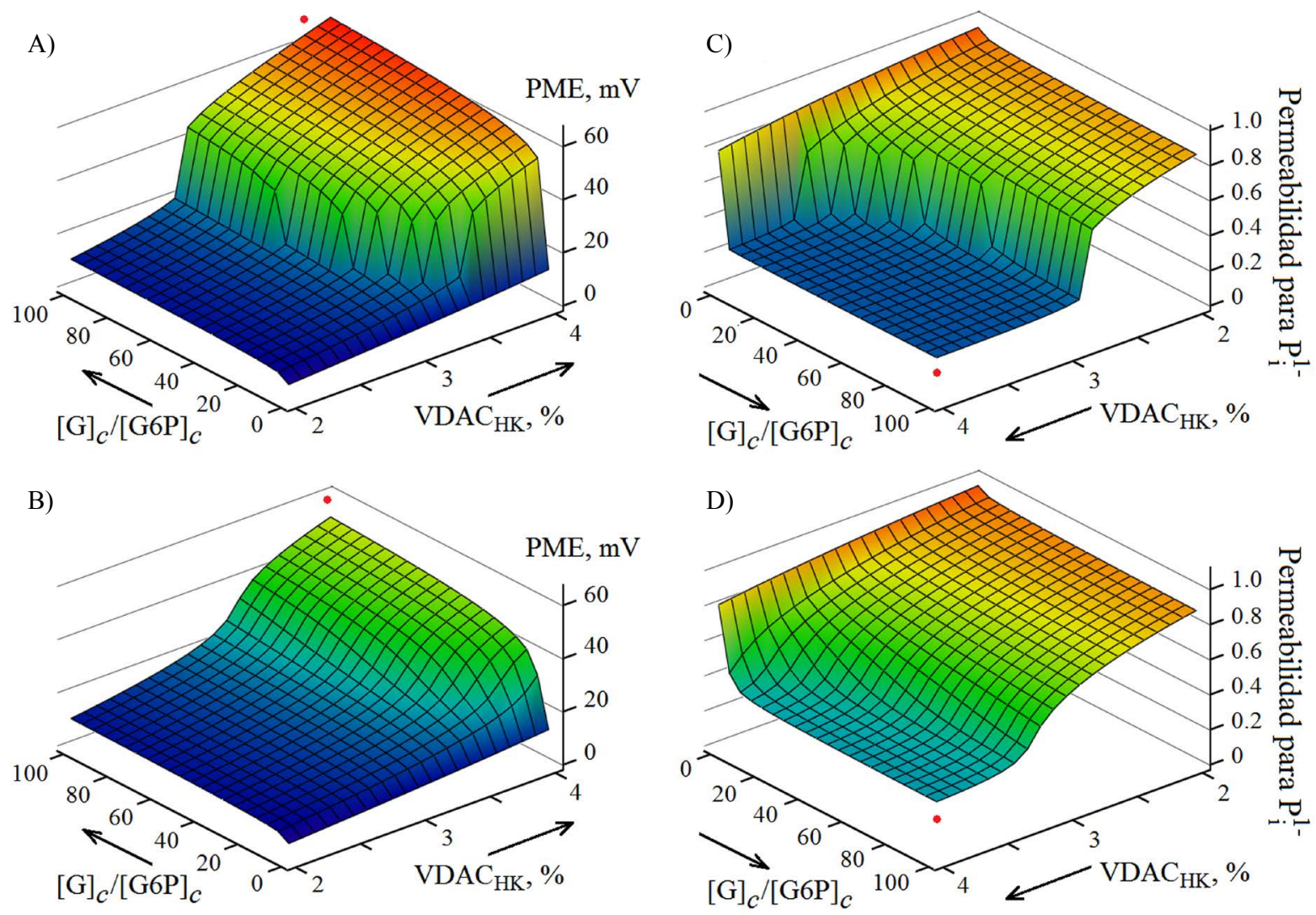

Figura 4. Evaluación computacional de los cambios del potencial de la membrana externa $(\mathrm{A}, \mathrm{B})$ y de la permeabilidad de la membrana externa al fosfato inorgánico (C,D) en función de la concentración de glucosa (de la relación $[\mathrm{G}]_{\mathrm{c}} /[\mathrm{G} 6 \mathrm{P}]_{\mathrm{c}}$ ) y del porcentaje de los VDAC que forman los complejos VDAC-HK en ausencia (A,C) y presencia de $10 \%$ de los VDAC no sensibles al voltaje (B,D) en la membrana externa. $S=40 \mathrm{~V}^{-1}$. Los puntos rojos indican que el potencial de mayor magnitud provoca un cambio más significativo de la permeabilidad de la membrana externa al fosfato inorgánico. 

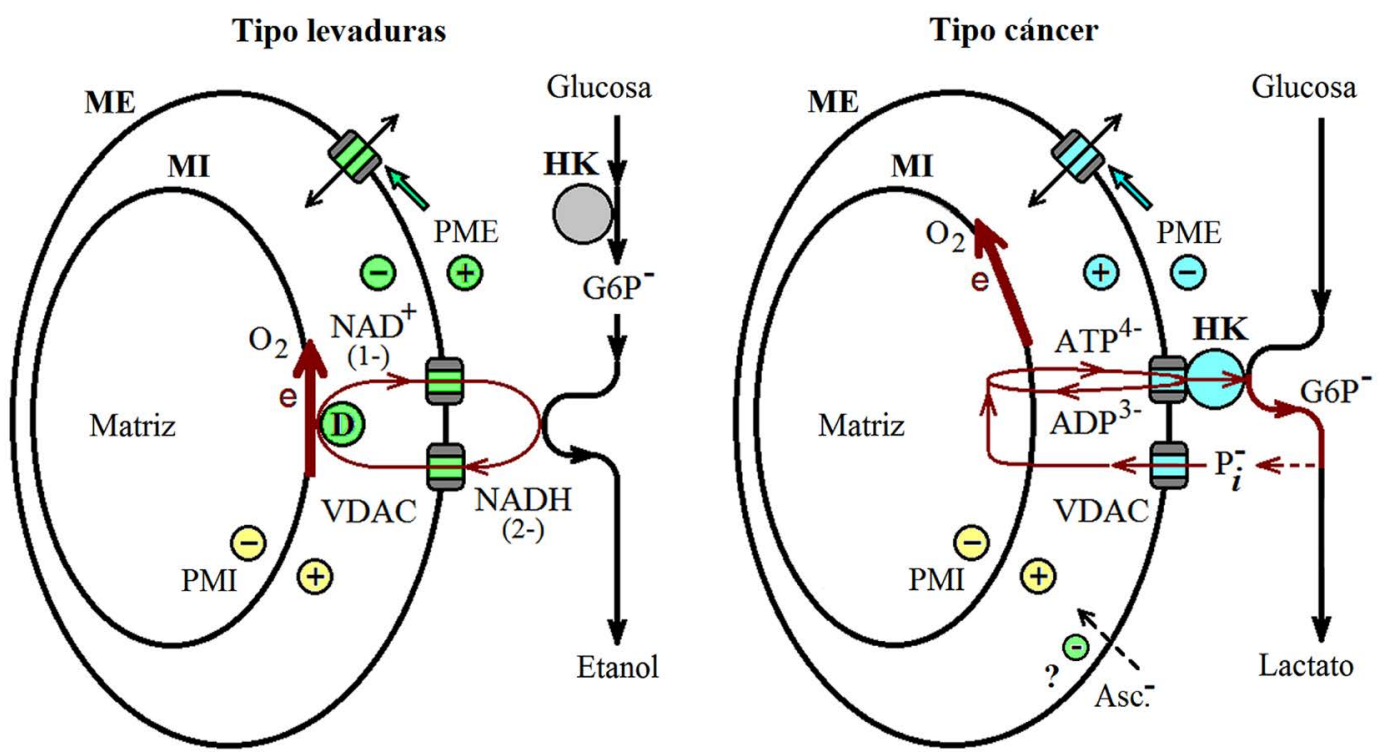

Figura 5. Posibles mecanismos de la supresión eléctrica de la respiración de las células mediante la generación del potencial negativo de la membrana externa acoplada a la circulación de $\mathrm{NADH}(2-) / \mathrm{NAD}^{+}(1-)$ a través de esta en la levadura $S$. cerevisiae, o mediante la generación del potencial positivo acoplada a la transferencia del grupo fosforilo a través de los complejos VDAC-HK de la membrana externa en células cancerígenas. Asc'.: se muestra que la oxidación del ascorbato en las mitocondrias de células cancerígenas podría causar una disminución del potencial positivo de la membrana externa generado por los complejos VDAC-HK.

posibilidad de la supresión eléctrica de la respira-ción de las mitocondrias debido al potencial generado (Lemeshko, 2002, 2014, 2015, 2017a, 2017b). La supresión de la respiración debida a los altos niveles de glucosa se conoce como efecto de Crabtree, pero no se sabe todavía si los procesos celulares responsables de esta inhibición (que es muy rápida, ocurre en segundos), son los mismos, o similares, para levaduras y las células cancerígenas (Hagman, et al., 2014; Pfeiffer \& Morley, 2014; Hammad, et al., 2016).

En estudios recientes se ha confirmado el efecto anticancerígeno del ácido ascórbico en concentraciones altas (Sen, et al., 2017; Xia, et al., 2017; Mastrangelo, et al., 2017), aunque el mecanismo no es todavía claro. No se descarta que ello se deba a la tendencia a generar potencial negativo de la membrana externa por la oxidación de ascorbato, como se muestra en la Figura 1B. De esta manera, la superposición de dos potenciales, el negativo, generado por la oxidación de ascorbato, y el positivo, generado por los complejos VDAC-HK (Figura 5), podría resultar en una disminución o incluso la cancelación de la supresión eléctrica de la respiración de las células cancerígenas con los consecuentes efectos anti-Crabtree, anti-Warburg y, en general, anticancerígenos.

Generación del potencial de la membrana externa mediante los complejos $C K-V D A C$. En los cardiomiocitos, el ATP mitocondrial se usa para la producción del $\mathrm{CrP}$ a partir de la creatina. En el espacio entre las membranas mitocondriales la enzima creatina cinasa $(\mathrm{CK})$ se encuentra unida a los VDAC, formando los complejos CK-VDAC (Figura 3D) y los ANT-CK-VDAC (Figura 3E).

En los cardiomiocitos y otras células, el intercambio rápido de fosfato de creatina con carga negativa y de creatina neutra entre las mitocondrias y los sarcómeros es primordial para la disminución de la resistencia de la ruta de suministro de energía durante la fase sistólica (Wallimann, et al., 2011; Simson, et al., 2016). La resistencia metabólica de esta ruta citosólica del intercambio $\mathrm{CrP}^{1-} / \mathrm{Cr}$ es mucho menor que la del intercambio por la electro-difusión del $\mathrm{ATP}^{4-}$ y $\mathrm{ADP}^{3-}$, sobre todo en concentraciones bajas de $\mathrm{ADP}^{3-}$ en el citosol (Wallimann, et al., 2011). Por otro lado, el flujo de los grupos fosforilo a través de los complejos CKVDAC (Figura 3D, $d$ ) puede causar la generación directa del potencial de la membrana externa, con el cierre de los VDAC libres sensibles al voltaje, y, finalmente, llevar a una restricción de la permeabilidad de la membrana externa a los metabolitos cargados (Lemeshko, 2016) mediante el mecanismo de control de realimentación negativa (Lemeshko, 2017a).

En el modelo CK-VDAC, la fuente para la generación del potencial de la membrana externa es la batería $E_{\mathrm{cv}}$ (Figura 3D, $d$ ), alimentada por la energía libre de Gibbs de la reacción de la creatina cinasa del mismo complejo:

$$
E_{c v}=\frac{\Delta G_{C K}^{o^{\prime}}}{F}+\frac{R T}{F} \ln \frac{[C r]_{c} \cdot[A T P]_{s}}{[C r P]_{c} \cdot[A D P]_{s}}
$$

donde $\Delta \mathrm{G}_{\mathrm{CK}}{ }^{0}=-12,7 \mathrm{~kJ} / \mathrm{mol}$ es la energía libre de Gibbs estándar de la reacción de la creatina cinasa; $[\mathrm{Cr}]_{\mathrm{c}} /[\mathrm{CrP}]_{\mathrm{c}}$ es la relación de las concentraciones de creatina y fosfato de creatina en el citosol; $[\mathrm{ATP}]_{\mathrm{s}} /[\mathrm{ADP}]_{\mathrm{s}}$ es la relación de las concentraciones de ATP y ADP en el espacio entre las membranas mitocondriales; $F$ es la constante de Faraday; 
$R$ es la constante universal de los gases, y $T=298 \mathrm{~K}$ es la temperatura del medio.

En este caso, el análisis termodinámico del modelo CKVDAC (Figura 3C) se hizo usando el sistema de ecuaciones, incluida la ecuación (17) (Lemeshko, 2016), y teniendo en cuenta las características cinéticas de la enzima $\mathrm{CK}$, con $K_{\mathrm{m}, \mathrm{Cr}}=10 \mathrm{mM}$. Para las evaluaciones se tomó la concentración total $[\mathrm{Cr}]+[\mathrm{CrP}]=25 \mathrm{mM}$, y la relación $[\mathrm{ATP}]_{\mathrm{s}} /[\mathrm{ADP}]_{\mathrm{s}}=500$ o $[\mathrm{ATP}]_{\mathrm{s}} /[\mathrm{ADP}]_{\mathrm{s}}=50$.

Los cálculos del modelo CK-VDAC en función de la concentración de creatina en el citosol, inmediatamente cercana de la membrana externa, demuestran la posibilidad de generar un potencial de la membrana externa relativamente alto (Figura 6A,B), para controlar la permeabilidad de los VDAC de dicha membrana. El nivel de la creatina, en el rango conocido de los cambios de la relación $[\mathrm{Cr}] /([\mathrm{Cr}]+$ [CrP]) durante las fases de sístole y diástole del corazón (Lemeshko, 2016), se incrementa significativamente durante
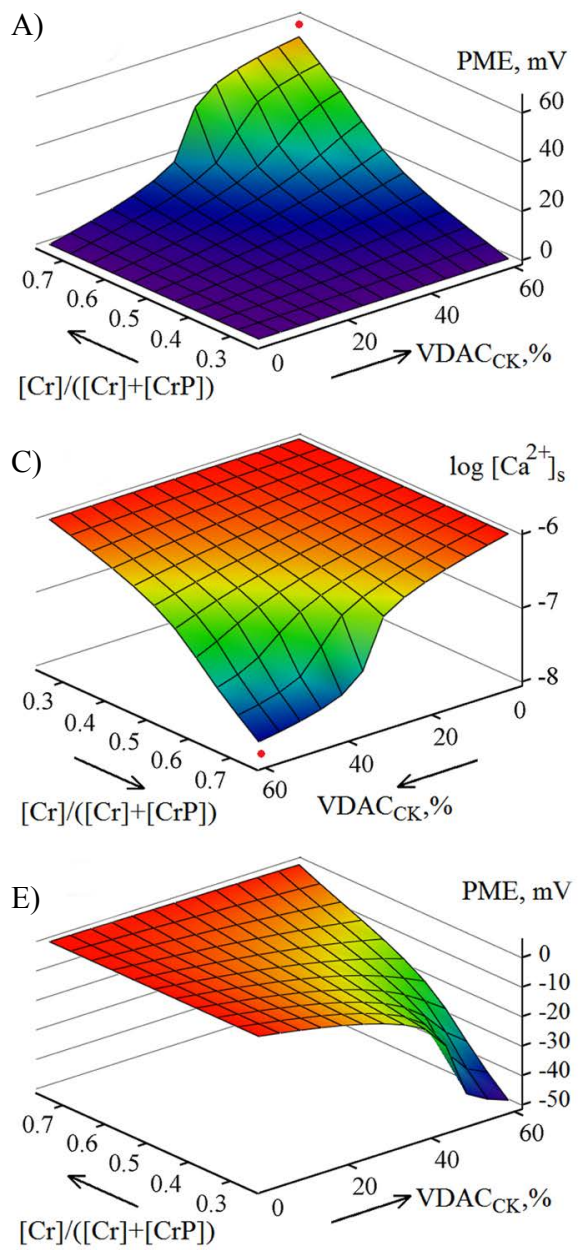

la fase sistólica debido al uso intensivo del CrP para recuperar localmente el ATP hidrolizado en los sarcómeros.

En el caso de ausencia de los VDAC libres no sensibles al voltaje en la membrana externa, el modelo demuestra una generación del potencial de hasta más de $50 \mathrm{mV}$ (Figura 6A), tomando una permeabilidad de $P_{\mathrm{c}}=0,1$ al $\mathrm{P}_{\mathrm{i}}^{-1}$ a través de los VDAC eléctricamente cerrados (Hodge \& Colombini, 1997). El potencial de la membrana externa disminuye a valores de hasta $40 \mathrm{mV}$ al considerar que $10 \%$ de los VDAC en la membrana externa no son sensibles al voltaje (Figura $6 \mathrm{~B}$ ). Cabe resaltar que estos valores del potencial positivo se calcularon para el caso del potencial de fosforilación del ATP mitocondrial tomado a $\Delta \mathrm{G}_{\mathrm{a}}=-61 \mathrm{~kJ} / \mathrm{mol}$ (Pinz, et al., 2008).

Según las evaluaciones termodinámicas del modelo, el cambio del potencial de la membrana externa desde un valor de casi cero durante la diástole hasta más de 30 $\mathrm{mV}$ durante la sístole (Figura 6A, B), permite mantener la concentración de $\mathrm{Ca}^{2+}$ en el espacio entre las membranas
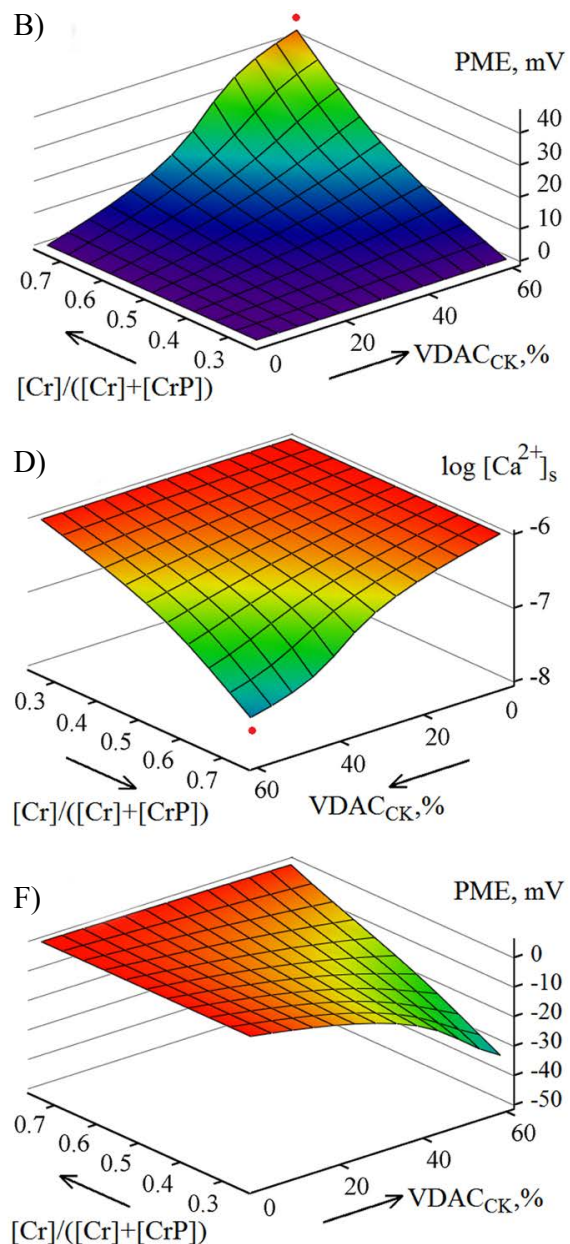

$[\mathrm{Cr}] /([\mathrm{Cr}]+[\mathrm{CrP}])$

Figura 6. Evaluación computacional del potencial de la membrana externa (A,B,E,F) y del nivel relativo de $\mathrm{Ca}^{2+}$ en el espacio entre las membranas mitocondriales (C,D) en función de la concentración de la creatina (de la relación $[\mathrm{Cr}] /([\mathrm{Cr}]+[\mathrm{CrP}]))$ y del porcentaje de los VDAC que forman los complejos CK-VDAC. Se supone que en el medio exterior se tiene $1 \mu \mathrm{M}$ de $\mathrm{Ca}^{2+}$; B,D,F: con $10 \%$ de los VDAC no sensibles al voltaje; $S=40 \mathrm{~V}^{-1} ;[\mathrm{Cr}]+[\mathrm{CrP}]=25 \mathrm{mM} ; \mathrm{A}-\mathrm{D}$ : $[\mathrm{ATP}]_{\mathrm{s}} /[\mathrm{ADP}]_{\mathrm{s}}=500\left(\Delta \mathrm{G}_{\mathrm{a}}=-61 \mathrm{~kJ} / \mathrm{mol}\right) ; \mathrm{E}, \mathrm{F}:[\mathrm{ATP}]_{\mathrm{s}} /[\mathrm{ADP}]_{\mathrm{s}}=50(\Delta \mathrm{G}=-54 \mathrm{~kJ} / \mathrm{mol})$. Los puntos rojos indican que el potencial de la membrana externa de mayor magnitud lleva a un cambio más significativo del nivel de $\mathrm{Ca}^{2+}$ en el espacio entre las membranas mitocondriales. 
mitocondriales a más de un orden de magnitud por debajo de su concentración en el sarcoplasma (Figura 6C, D). Esta función del potencial de mantener la concentración relativamente baja de $\mathrm{Ca}^{2+}$ en el espacio entre las membranas mitocondriales con respecto al citosol durante la sístole, parece ser importante para disminuir significativamente la velocidad de transporte de $\mathrm{Ca}^{2+}$ a la matriz mitocondrial y proteger de esta manera a las mitocondrias contra la apertura del poro de transición de permeabilidad mitocondrial (PTP).

Se sabe que la concentración de $\mathrm{Ca}^{2+}$ durante la sístole puede alcanzar hasta $1 \mu \mathrm{M}$ en el sarcoplasma (Eisner, $\boldsymbol{e t}$ al., 2017), y hasta más de $10 \mu \mathrm{M}$ en los microdominios entre las mitocondrias y el retículo sarcoplásmico adyacente (Rizzuto, et al., 2012). En caso de que el potencial positivo de la membrana externa no se genere durante la sístole, la concentración de $\mathrm{Ca}^{2+}$ en el espacio entre las membranas mitocondriales debe alcanzar niveles de 1 a $10 \mu \mathrm{M}$. Con esto, el flujo de calcio a la matriz mitocondrial incrementaría por lo menos en un orden de magnitud, en comparación con el transporte durante la diástole, ya que la constante $K_{\mathrm{m}, \mathrm{Ca}}{ }^{2+}$ del transportador de $\mathrm{Ca}^{2+}$ en la membrana interna es de 5 a $10 \mu \mathrm{M}$ (Carafolli, 2012). Aunque en la fase inicial de la sístole, cuando la relación $[\mathrm{Cr}] /([\mathrm{Cr}]+[\mathrm{CrP}])$ y el potencial generado no alcanzan sus magnitudes máximas todavía (Figura 6A, B), la velocidad de acumulación de $\mathrm{Ca}^{2+}$ en las mitocondrias puede ser elevada. Por otro lado, la concentración estacionaria de $\mathrm{Ca}^{2+}$ en la matriz mitocondrial depende también de la capacidad del sistema de extrusión de $\mathrm{Ca}^{2+}$ desde la matriz mitocondrial, parte del cual es el antiportador $\mathrm{Ca}^{2+} / \mathrm{Na}^{+}$de la membrana interna (Eisner, et al., 2017).

El modelo también evidencia que en el caso de un potencial de fosforilación del ATP mitocondrial relativamente bajo (ecuación 15), del orden de $\Delta \mathrm{G}_{\mathrm{a}}=-54 \mathrm{~kJ} / \mathrm{mol}$, o sea cuando la relación $[\mathrm{ATP}]_{\mathrm{s}} /[\mathrm{ADP}]_{\mathrm{s}}$ equivale a $50 \mathrm{en}$ vez de 500 en la ecuación (17), el potencial de la membrana externa calculado es negativo para la diástole, de (-30)-(-50) mV (Figura 6E, F), y llega a ser cero durante la sístole, debido al incremento del nivel de la creatina. Esto es indicativo del riesgo de la apertura del PTP por acción del $\mathrm{Ca}^{2+}$ sistólico, lo cual conlleva daños mitocondriales, cuando el potencial energético mitocondrial es relativamente bajo, como, por ejemplo, durante la hipoxia.

Para las mitocondrias de corazón y cerebro también se ha reportado la presencia de los complejos triples ANTCK-VDAC, los cuales permiten transferir el grupo fosforilo desde el ATP de la matriz mitocondrial directamente a la creatina del citosol (Brdiczka, et al., 2006) a través de las dos membranas mitocondriales. El análisis termodinámico de este modelo (Figura 3E, $e$ ) ha mostrado que el potencial calculado, positivo o negativo, de la membrana externa depende del estado energético tanto del citosol como de las mitocondrias (Lemeshko, 2017a).

\section{Observaciones experimentales a favor de la generación del potencial eléctrico de la membrana mitocondrial externa}

Las restricciones significativas de los flujos de los metabolitos de carga negativa entre las mitocondrias y el citosol han sido reportadas por varios autores (Vander Heiden, et al., 2000; Lemasters \& Holmuhamedov, 2006; Rostovtseva \& Bezrukov, 2012; Simson, et al., 2016). Hasta el momento, la explicación más aceptada sobre el mecanismo de regulación de la permeabilidad de la membrana externa es el "taponamiento" molecular de los VDAC. Se supone que la generación del potencial de la membrana externa es imposible porque su permeabilidad es alta para iones pequeños, aunque se reconoce que la generación del potencial podría explicar varios casos de la supresión global de mitocondrias en células normales y cancerígenas (Lermasters \& Holmuhamedov, 2006).

En este sentido, cabe resaltar que normalmente los iones de potasio, sodio y cloro no participan en procesos estacionarios en la membrana externa, y deben alcanzar su equilibrio electroquímico dependiendo del potencial de esta mantenido por un mecanismo estacionario (Figura 3) dependiente del metabolismo energético mitocondrial. Se puede considerar que el movimiento de los iones pequeños a través de la membrana externa (Figura 3B), o su escape, es el proceso de carga de un condensador electrolítico, $\mathrm{C}_{\mathrm{o}}$, de dicha membrana (Figura 3B, b), causando un retraso en la generación del potencial. Para profundizar estos aspectos dinámicos, sobre todo en el caso de los cambios de las fases de diástole y sístole del corazón, se debe desarrollar un modelo más complejo, de tipo cinético.

La generación del potencial de la membrana externa puede afectar la monitorización experimental del potencial de la membrana interna con sondas iónicas fluorescentes, permeables a través de biomembranas. Hasta el momento, la posibilidad de la interferencia del potencial de la membrana externa, tan evidente en términos de la termodinámica (Figura 7), no se tiene en cuenta en varias aplicaciones de este método (Zorova, et al., 2017).

Sin embargo, se han reconocido ciertas dificultades para evaluar cuantitativamente el potencial de la membrana interna en células vivas (Lemasters \& Ramshesh, 2007; Gerencser, et al., 2012), especialmente por la interferencia del potencial de la membrana plasmática con la monitorización en células vivas mediante microscopía óptica usando sondas iónicas de fluorescencia (Gerencser, et al., 2012).

Con el fin de evitar este problema, se ha propuesto medir la intensidad de la fluorescencia del catión permeable éster metílico de tetrametilrodamina $\left(\mathrm{TMRM}^{+}\right)$dentro de mitocondrias $\left(I F_{\mathrm{i}}\right)$ y en el espacio exterior de estas $\left(I F_{\mathrm{o}}\right)$ (Lemasters \& Ramshesh, 2007), cuantificando el potencial de la membrana interna según la ecuación de Nernst:

$$
P M I=-\frac{R T}{F} \ln \frac{I F_{i}}{I F_{o}}
$$




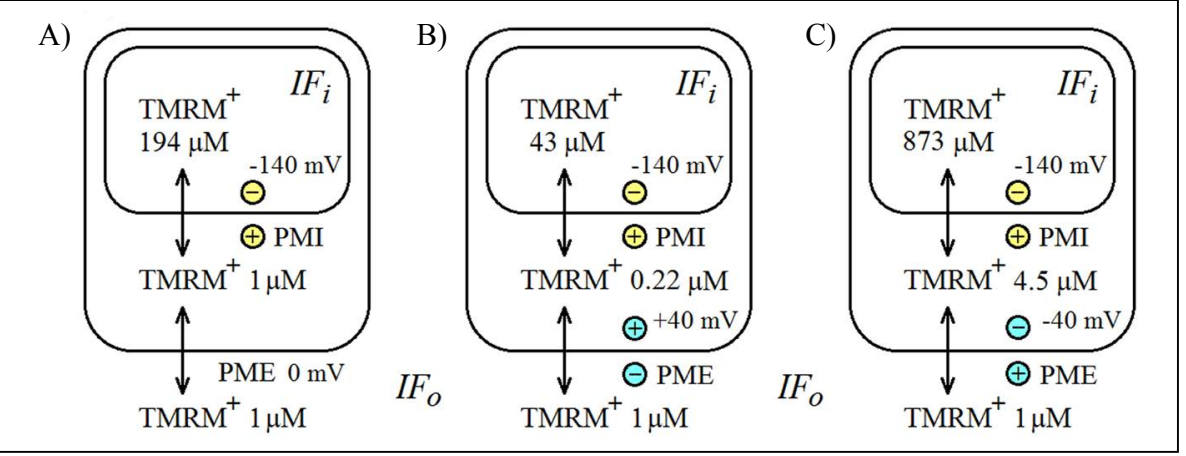

Figura 7. Posible influencia del potencial de la membrana externa (PME) sobre la acumulación de la sonda catiónica fluorescente TMRM ${ }^{+}$ en la matriz de las mitocondrias energizadas, con potencial fijo de la membrana interna $(-140 \mathrm{mV})$. A: $\mathrm{PME}=0 \mathrm{mV} ; \mathrm{B}$ : $\mathrm{PME}=+40 \mathrm{mV}$; : $\mathrm{PME}=-40 \mathrm{mV}$

Es muy obvio que la ecuación (18) es aplicable solamente cuando el potencial de la membrana externa es igual a cero (Figura 7A), y no así cuando es positivo (Figura 7B) o negativo (Figura 7C), ya que la concentración del catión $\mathrm{TMRM}^{+}$en el espacio entre las membranas mitocondriales, con respecto a la de su medio externo, depende del signo y el valor de dicho potencial (Figura 7).

En general, cuando el potencial de la membrana externa es $\neq 0$, se debería usar la ecuación de Nernst teniendo en cuenta ambos potenciales, el de la membrana interna y el de la externa:

$$
P M I+P M E=-\frac{R T}{F} \ln \frac{I F_{i}}{I F_{o}}
$$

Se ha demostrado que el knockdown de los VDAC1 y VDAC2 en células cancerígenas HepG2 lleva a una disminución de la intensidad de fluorescencia mitocondrial del $\mathrm{TMRM}^{+}$de 42 y $58 \%$, respectivamente, sin cambio estadísticamente significativo de la intensidad de la fluorescencia de los nucleótidos de piridina NAD(P)H (Maldonado, et al., 2013). Dado que el nivel de los $\mathrm{NAD}(\mathrm{P}) \mathrm{H}$ en la matriz mitocondrial depende del potencial de la membrana interna (Lemeshko, et al., 2006a), se puede suponer que este no cambia en estos experimentos. Por otro lado, la disminución o la inhibición de los VDAC libres en la membrana externa debe influir significativamente en la probabilidad de generación de su potencial, incrementando la resistencia $R_{v}$ (Figura $3 b$ ). Los posibles cambios de dicho potencial se pueden evaluar en los experimentos mencionados (Maldonado, et al., 2013) aplicando la ecuación (19) antes y después del knockdown con el potencial de la membrana interna invariable. Por último, los cambios del potencial de la membrana externa se pueden estimar según la ecuación:

$$
\triangle P M E=-\frac{R T}{F} \ln \frac{I F_{i, k d}}{I F_{i}}
$$

donde $I F_{\mathrm{i}}$ y $I F_{\mathrm{i}, \mathrm{kd}}$ son las intensidades de la fluorescencia mitocondrial del $\mathrm{TMRM}^{+}$antes y después del knockdown. Según la ecuación (20), con $I F_{\mathrm{i}}=100 \%$, los cálculos de
$I F_{\mathrm{i}, \mathrm{kd}}=42 \%$ e $I F_{\mathrm{i}, \mathrm{kd}}=58 \%$, ya mencionados, evidencian un incremento del potencial de la membrana externa de $15 \mathrm{mV}$ y $23 \mathrm{mV}$, respectivamente.

Algunos tratamientos de las células HepG2 llevan al aumento de la concentración de la tubulina libre en el citosol, causando una disminución de 60 a $70 \%$ en la intensidad de la fluorescencia mitocondrial del $\mathrm{TMRM}^{+}$(Maldonado, et al., 2010), lo cual podría deberse a un incremento del potencial de la membrana externa de 24 a $32 \mathrm{mV}$, según la ecuación (20). El cambio de dicho potencial respondería (Figura $3, a-e$ ) al incremento de la resistencia $R_{\mathrm{v}}$ de la membrana externa debido al conocido "taponamiento" molecular de los VDAC con tubulina (Rostovtseva \& Bezrukov, 2012; Maldonado, et al., 2013; Rostovtseva, et al., 2015), la cual, además, incrementa su sensibilidad al potencial de la membrana externa. Por otro lado, un tratamiento de las células que conlleve la disminución de la concentración de la tubulina libre en el citosol causa un efecto contrario, un incremento de $65 \%$ en la intensidad de la fluorescencia mitocondrial del $\mathrm{TMRM}^{+}$(Maldonado, et al., 2010). En este caso, según la ecuación (20), el aumento de los VDAC libres resultaría en una disminución de $13 \mathrm{mV}$ del potencial de la membrana externa.

En general, y según el modelo VDAC-HK de generación del potencial de la membrana externa (Figura 3B), los factores que interactúan con los VDAC evitando la formación de los complejos VDAC-HK y disminuyendo de esta manera la probabilidad de generación de dicho potencial, deben causar el efecto anti-Warburg (Lemeshko, 2014, 2015, 2017a). Estas predicciones sustentarían la consideración del VDAC como un blanco importante para el desarrollo de nuevos medicamentos y tecnologías anticancerígenas (Camara, et al., 2017; Shoshan-Barmatz, et al., 2015, 2017).

Hemos desarrollado y patentado nuevos péptidos con actividad anticancerígena y antimicrobiana (Lemeshko, $\boldsymbol{e t}$ al., 2006b; Orduz \& Lemeshko, 2016), en tanto que en los ensayos preliminares con nuevos péptidos diseñados para impedir la formación de los complejos VDAC-HK, se ha demostrado también una elevada actividad anticancerígena 
en cultivos celulares. Los datos experimentales obtenidos concuerdan con los modelos propuestos de generación del potencial de la membrana externa (Lemeshko, 2002, 2014, 2015, 2017a) y con la actividad anticancerígena de esta clase de péptidos (Shoshan-Barmatz, et al., 2015, 2017).

En colaboración con el MD Anderson Cancer Center (Texas), se ha demostrado que las avicinas, triterpenoides naturales, hacen permeable la membrana externa (Lemeshko, et al., 2006a; Haridas, et al., 2007), lo que debería disminuir el valor de su potencial generado en células tumorales. Además, en estos estudios se ha visto que el grado de permeabilidad de la membrana externa a las avicinas puede ser tan elevado como para producir la salida del citocromo $\mathrm{C}$ desde las mitocondrias.

La generación del potencial de la membrana externa puede ser crucial en el control del estado energético del corazón. Se sabe que el valor de la $K_{\mathrm{m}, \mathrm{ADP}}$ aparente para activar la respiración de los cardiomiocitos permeabilizados es mucho más grande en ausencia de la creatina que en su presencia (Appaix, et al., 2003; Timohhina, et al., 2009; Saks, et al., 2010). Con la generación de un potencial positivo de la membrana externa en presencia de creatina (Figura 3D, E), la concentración de ADP en el espacio entre las membranas mitocondriales debe incrementarse significativamente con respecto al medio exterior (Figura 8), provocando la activación significativa de la respiración mitocondrial, a pesar de su concentración relativamente baja en el medio exterior. Por ejemplo, si la diferencia de las concentraciones de ADP en el espacio entre las membranas mitocondriales fuera de 10 veces en presencia de creatina, comparada con su ausencia, ello se debería a la generación de un potencial de la membrana externa de $20 \mathrm{mV}$ (según la ecuación de Nernst) debida a la actividad de la creatina cinasa en presencia de creatina (Figura 8).
En mitocondrias aisladas de corazón incubadas con $1 \mu \mathrm{M}$ de tubulina, se ha reportado que la $K_{\mathrm{m}, \mathrm{ADP}}$ aparente disminuye 14,3 veces en presencia de $20 \mu \mathrm{M}$ de creatina (Timohhina, et al., 2009). Se puede esperar que mediante la actividad de la creatina cinasa en presencia de la creatina se genere un potencial de la membrana externa de aproximadamente 24 $\mathrm{mV}$, causando la acumulación del $\mathrm{ADP}^{3-}$ en el espacio entre las membranas mitocondriales y un incremento significativo de la respiración de las mitocondrias.

Como se ve en la Figura 8, la generación del potencial positivo de la membrana externa puede incrementar la resistencia de las mitocondrias frente a niveles altos de $\mathrm{Ca}^{2+}$. Se ha demostrado, por ejemplo, que la adición de $30 \mu \mathrm{M}$ de $\mathrm{Ca}^{2+}$ a la suspensión de mitocondrias de corazón lleva a la activación del poro de transición de permeabilidad mitocondrial (Dolder, et al., 2003); para obtener el mismo efecto en presencia de creatina, se deben añadir $90 \mu \mathrm{M} \mathrm{Ca}^{2+}$ (Dolder, et al., 2003). Lo anterior se puede explicar por la extrusión de $\mathrm{Ca}^{2+}$ desde el espacio entre las membranas mitocondriales debida a la generación de un potencial positivo de la membrana externa de unos $15 \mathrm{mV}$.

El análisis de los datos experimentales permite plantear que la generación del potencial positivo de la membrana externa por el sistema VDAC-creatina cinasa o VDAChexocinasa podría ser crucial para la protección de las células contra la muerte en las condiciones de niveles tóxicos de calcio en el citosol. Es importante anotar que el valor y el signo del potencial de la membrana externa deben resultar de la superposición de los potenciales eléctricos generados mediante varios mecanismos. Las evaluaciones termodinámicas de los mecanismos descritos en este trabajo demuestran que hay una probabilidad alta de que se genere un potencial de la membrana externa con un valor suficiente (entre $-40 \mathrm{mV}$ $\mathrm{y}+40 \mathrm{mV}$ ) para modular profundamente la permeabilidad

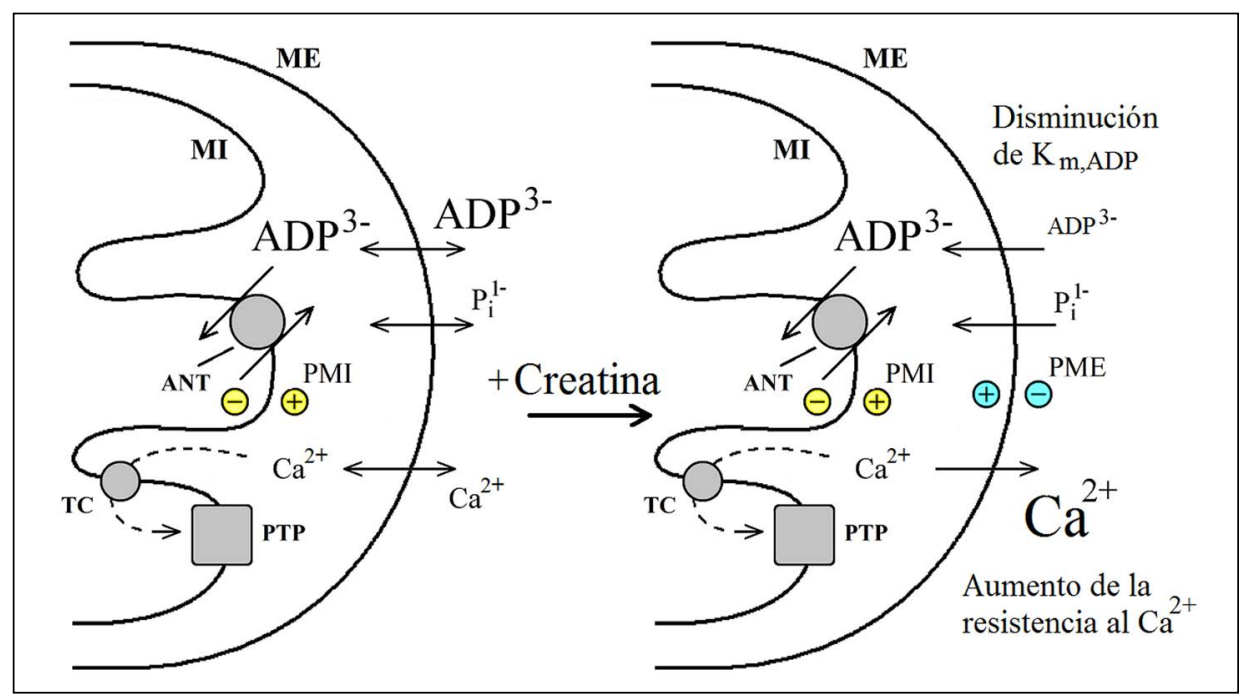

Figura 8. La generación del potencial positivo de la membrana externa en las mitocondrias de corazón en presencia de creatina puede ser un factor crucial para una disminución significativa de la $K_{\mathrm{m}, \mathrm{ADP}}$ aparente de la respiración mitocondrial y para una elevada resistencia al Ca ${ }^{2+}$ durante la sístole. ANT: antiportador ATP/ADP; PTP: poro de transición de permeabilidad mitocondrial; TC: canal de Ca ${ }^{2+}$ 
del VDAC frente a varios metabolitos con carga negativa. En general, la membrana mitocondrial externa puede tener un papel crucial en el control del metabolismo energético celular atendiendo a las propiedades de regulación del VDAC mediante el voltaje (voltage-gating) (Colombini \& Mannella, 2012).

En los últimos años, diversos investigadores en este campo han considerado la posibilidad de generar el potencial de la membrana externa (Camara, et al., 2017; Rostovtseva, et al., 2017; Lemasters, 2017; Shoshan-Barmatz, et al., 2018). Uno de los factores que puede favorecer la generación de dicho potencial es el "taponamiento" molecular de una fracción de los VDAC en la membrana externa con algunas proteínas (Lemeshko, 2017a) como la tubulina (Rostovtseva \& Bezrukov, 2012), o la $\alpha$-sinucleina (Rostovtseva, et al., 2015), entre otras, lo que reviste gran interés para aclarar el papel del VDAC en varias enfermedades neurodegenerativas (Rostovtseva, et al., 2015; Camara, et al., 2017; Shoshan-Barmatz, et al., 2018).

\section{Conclusiones}

Con los mecanismos propuestos para la generación del potencial eléctrico en la membrana mitocondrial externa de células normales y tumorales, y con las predicciones termodinámicas del posible rango de los cambios de dicho potencial, es posible explicar varios fenómenos de la regulación del metabolismo energético y de la resistencia a la muerte celular. Por ejemplo, los efectos de Crabtree y Warburg, que todavía no son claros, podrían estar asociados con la supresión eléctrica de las mitocondrias tanto en las células cancerígenas como en la levadura $S$. cerevisiae. Según el modelo de generación del potencial de la membrana externa por la acción de los complejos VDAC-hexocinasa, los cuales actuarían como una batería biológica, se puede predecir que aquellos factores que impiden la formación de estos complejos tendrían una actividad anticancerígena. Dadas las diversas posibilidades de generación del potencial de la membrana externa de manera dependiente del metabolismo, la membrana mitocondrial externa puede ejercer un control eléctrico del flujo metabólico entre las mitocondrias y el citosol mediante el mecanismo de realimentación negativa. Incluso cuando los niveles del potencial son relativamente bajos y no bastan para el cierre eléctrico de los VDAC, el potencial generado puede influir significativamente en las concentraciones de los metabolitos cargados y del $\mathrm{Ca}^{2+}$ en el espacio entre las membranas mitocondriales, modulando de esta manera el estado metabólico de las mitocondrias y la resistencia a la muerte celular bajo la influencia de varios factores adversos. El desarrollo de nuevos métodos para la confirmación experimental directa de la generación del potencial de la membrana externa en las células vivas es crucial para aclarar el papel fisiológico de las propiedades reguladoras del VDAC mediante el voltaje, las cuales se han conservado a lo largo de la evolución biológica (Colombini \& Mannella, 2012).

\section{Agradecimientos}

El autor expresa sus profundos agradecimientos a la Universidad Nacional de Colombia, sede Medellín, por las facilidades brindadas para desarrollar las investigaciones; al profesor Sergio Orduz Peralta, de la Universidad Nacional de Colombia, sede Medellín, coautor de las patentes de péptidos antimicrobianos, anticancerígenos e insecticidas; al profesor José Alexander Álvarez Bustamante, de la Universidad CES, coautor de la patente de una máquina 'electroporadora' de láminas orgánicas; a los compañeros de trabajo, profesores Dairo Alonso Rendón Rivera y Diego Aristizábal Ramírez, por la lectura de este artículo y sus valiosas observaciones. Asimismo, el autor agradece al doctor Marco Colombini, de la Universidad Maryland (EE. UU.), por su apoyo e interés permanente en los trabajos teóricos mencionados, y a la doctora Tatiana Rostovtseva, de los National Institutes of Health de Estados Unidos, por la asesoría sobre las propiedades eléctricas de los VDAC.

\section{Conflicto de intereses}

El autor declara no tener conflicto de intereses con respecto al contenido de este artículo original.

\section{Referencias}

Appaix F., Kuznetsov A.V., Usson Y., Kay L., Andrienko T., Olivares J., Kaambre T., Sikk P., Margreiter R., Saks V. (2003). Possible role of cytoskeleton in intracellular arrangement and regulation of mitochondria. Exp Physiol. 88: $175-190$.

Avéret N., Aguilaniu H., Bunoust O., Gustafsson L., Rigoulet M. (2002). NADH is specifically channeled through the mitochondrial porin channel in Saccharomyces cerevisiae. J Bioenerg Biomembr. 34 (6): 499-506.

Bakker B.M., Overkamp K.M., van Maris A.J., Kötter P., Luttik M.A., van Dijken J.P., Pronk J.T. (2001). Stoichiometry and compartimentation of NADH metabolism in Saccharomyces cerevisiae. FEMS Microbiol Rev. 25 (1): 15-37.

Benz R., Kottke M., Brdiczka D. (1990). The cationically selective state of the mitochondrial outer membrane pore: A study with intact mitochondria and reconstituted mitochondrial porin. Biochim Biophys Acta. 1022: 311-318.

Brdiczka D.G., Zorov D.B., Sheu S.S. (2006). Mitochondrial contact sites: Their role in energy metabolism and apoptosis. Biochim. Biophys. Acta. 1762: 148-163.

Camara A.K.S., Zhou Y., Wen P.C., Tajkhorshid E., Kwok W.M. (2017). Mitochondrial VDAC1: A Key Gatekeeper as Potential Therapeutic Target. Front Physiol. 8: 460.

Carafoli E. (2012). The interplay of mitochondria with calcium: An historical appraisal. Cell Calcium. 52 (1): 1-8.

Colombini M. (1979). A candidate for the permeability pathway of the outer mitochondrial membrane. Nature. 279: 643-645.

Colombini M. (2016). The VDAC channel: Molecular basis for selectivity. Biochim Biophys Acta. 1863 (10): 2498-2502.

Colombini M., Blachly-Dyson E., Forte M. (1996). VDAC, a channel in the outer mitochondrial membrane. Ion Channels. 4: 169-202. 
Colombini M., Mannella C.A. (2012). VDAC, the early days. Biochim Biophys Acta. 1818 (6): 1438-1443.

Díaz-Ruiz R., Rigoulet M., Devin A. (2011). The Warburg and Crabtree effects: On the origin of cancer cell energy metabolism and of yeast glucose repression. Biochim Biophys Acta. 1807 (6): 568-576.

Dolder M., Walzel B., Speer O., Schlattner U., Wallimann T. (2003). Inhibition of the mitochondrial permeability transition by creatine kinase substrates. Requirement for microcompartimentation. J Biol Chem. 278: 17760-17766.

Earnshaw M.J. (1975). The mechanism of K+-stimulated exogenous NADH oxidation in plant mitochondria. FEBS Lett. 59 (1): 109-112.

Eisner D.A., Caldwell J.L., Kistamás K., Trafford A.W. (2017). Calcium and excitation-contraction coupling in the heart. Circ Res. 121 (2): 181-195.

Hagman A., Säll T., Piškur J. (2014). Analysis of the yeast shortterm Crabtree effect and its origin. FEBS J. 281 (21): 48054814

Hammad N., Rosas-Lemus M., Uribe-Carvajal S., Rigoulet M., Devin A. (2016). The Crabtree and Warburg effects: Do metabolite-induced regulations participate in their induction? Biochim Biophys Acta. 1857 (8): 1139-1146.

Haridas V., Li X., Mizumachi T., Higuchi M., Lemeshko V.V., Colombini M., Gutterman J.U. (2007). Avicins, a novel plant-derived metabolite lowers energy metabolism in tumor cells by targeting the outer mitochondrial membrane. Mitochondrion. 7 (3): 234-240.

Hodge T., Colombini M. (1997). Regulation of metabolite flux through voltage-gating of VDAC channels. J Membr Biol. 157 (3): 271-279.

Gerencser A.A., Chinopoulos C., Birket M.J., Jastroch M., Vitelli C., Nicholls D.G., Brand M.D. (2012). Quantitative measurement of mitochondrial membrane potential in cultured cells: Calcium-induced de- and hyperpolarization of neuronal mitochondria. J Physiol. 590 (12): 2845-2871.

John S., Weiss J.N., Ribalet B. (2011). Subcellular localization of hexokinases I and II directs the metabolic fate of glucose. PLoS One. 6 (3): e17674.

Kmita H., Budzińska M., Stobienia O. (2003). Modulation of the voltage-dependent anionselective channel by cytoplasmic proteins from wild type and the channel depleted cells of Saccharomyces cerevisiae. Acta Biochim Pol. 50 (2): 415-424.

Lemasters J.J. \& Holmuhamedov E. (2006). Voltage-dependent anion channel (VDAC) as mitochondrial governator thinking outside the box. Biochim Biophys Acta. 1762 (2): 181-190.

Lemasters J.J. \& Ramshesh V.K. (2007). Imaging of mitochondrial polarization and depolarization with cationic fluorophores. Methods Cell Biol. 80: 283-295.

Lemasters J.J. (2017). Evolution of voltage-dependent anion channel function: From molecular sieve to governator to actuator of ferroptosis. Front Oncol. 7: 303.

Lemeshko S.V. \& Lemeshko V.V. (2000). Metabolically derived potential on the outer membrane of mitochondria: a computational model. Biophys J. 79: 2785-2800.

Lemeshko V.V. (2002). Model of the outer membrane potential generation by the inner membrane of mitochondria. Biophys J. 82: 684-692.
Lemeshko V.V. (2006). Theoretical evaluation of a possible nature of the outer membrane potential of mitochondria. Eur Biophys J. 36: 57-66.

Lemeshko V.V., Haridas V., Quijano Pérez J.C., Gutterman J.U. (2006a). Avicins, natural anticancer saponins, permeabilize mitochondrial membranes. Arch Biochem Biophys. 454 (2): 114-122.

Lemeshko V., Guzmán F., Patarroyo M.E., Segura C., Orduz S. (2006b) Synthetic peptide having an ionophoric and antimicrobial activity. United States Patent No. 7041647.

Lemeshko V.V. (2014). VDAC electronics: 1. VDAC-hexo(gluco) kinase generator of the mitochondrial outer membrane potential. Biochim Biophys Acta. 1838: 1362-1371.

Lemeshko V. (2015). The Warburg effect as a VDAC-hexokinasemediated electrical suppression of mitochondrial energy metabolism. FASEB J. 29 (Suppl 1): 725-27.

Lemeshko V.V. (2016). VDAC electronics: 3. VDAC-creatine kinase-dependent generation of the outer membrane potential in respiring mitochondria. Biochim Biophys Acta. 1858 (7 PtA): 1411-1418.

Lemeshko V.V. (2017a). The mitochondrial outer membrane potential as an electrical feedback control of cell energy metabolism. En: T.K. Rostovtseva (Ed.), Molecular Basis for Mitochondrial Signaling, Springer International Publishing, New York, Chapter 9: 217-250.

Lemeshko V.V. (2017b). VDAC electronics: 4. Novel electrical mechanism and thermodynamic estimations of glucose repression of yeast respiration. Biochim Biophys Acta. 1859 (11): 2213-2223.

Liu M.Y. \& Colombini M. (1992). A soluble mitochondrial protein increases the voltage dependence of the mitochondrial channel, VDAC. J Bioenerg Biomembr. 24: 41-46.

Luttik M.A., Overkamp K.M., Kötter P., de Vries S., van Dijken J.P., Pronk J.T. (1998). The Saccharomyces cerevisiae NDE1 and NDE2 genes encode separate mitochondrial NADH dehydrogenases catalyzing the oxidation of cytosolic NADH. J Biol Chem. 273 (38): 24529-24534.

Maldonado E.N., Patnaik J., Mullins M.R., Lemasters J.J. (2010). Free tubulin modulates mitochondrial membrane potential in cancer cells. Cancer Res. 70 (24): 10192-10201.

Maldonado E.N., Sheldon K.L., DeHart D.N., Patnaik J., Manevich Y., Townsend D.M., Bezrukov S.M., Rostovtseva T.K., Lemasters J.J. (2013). Voltage-dependent anion channels modulate mitochondria metabolism in cancer cells: Regulation by free tubulin and erastin. J Biol Chem. 288 (17): 11920-11929.

Mannella C.A. (1982). Structure of the outer mitochondrial membrane: Ordered arrays of porelike subunits in outermembrane fractions from Neurospora crassa mitochondria. J Cell Biol. 94: 680-687.

Marín-Hernández A., Rodríguez-Enríquez S., Vital-González P.A., Flores-Rodríguez F.L., Macías-Silva M., SosaGarrocho M., Moreno-Sánchez R. (2006). Determining and understanding the control of glycolysis in fast-growth tumor cells. Flux control by an overexpressed but strongly product-inhibited hexokinase. FEBS J. 273 (9): 1975-1988.

Mastrangelo D., Pelosi E., Castelli G., Lo-Coco F., Testa U. (2017). Mechanisms of anti-cancer effects of ascorbate: Cytotoxic activity and epigenetic modulation. Blood Cells Mol Dis pii. S1079-9796 (17): 30327-3. 
O'Gorman E., Beutner G., Dolder M., Koretsky A.P., Brdiczka D., Wallimann T. (1997). The role of creatine kinase in inhibition of mitochondrial permeability transition. FEBS Lett. 414: 253-257.

Ohnishi T., Kawaguchi K., Hagihara B. (1966). Preparation and some properties of yeast Mitochondria. J Biol Chem. 241 (8): 1797-1806.

Orduz S., Lemeshko V. (2016). Péptido sintético policatiónico como agente ionofórico, antimicrobiano, antitumoral e insecticida. Rad. Gaceta 701, No. 174, 31 de julio de 2014, Superintendencia de Industria y Comercio de Colombia. Res. No.: 22123.

Pfeiffer T., Morley A. (2014). An evolutionary perspective on the Crabtree effect. Front Mol Biosci. 1: 17.

Pinz I., Ostroy S.E., Hoyer K., Osinska H., Robbins J., Molkentin J.D., Ingwall J.S. (2008). Calcineurin-induced energy wasting in a transgenic mouse model of heart failure. Am J Physiol Heart Circ Physiol. 294 (3): H1459-H1466.

Porcelli A.M., Ghelli A., Zanna C., Pinton P., Rizzuto R., Rugolo M. (2005). $\mathrm{pH}$ difference across the outer mitochondrial membrane measured with a green fluorescent protein mutant. Biochem Biophys Res Commun. 326: 799-804.

Rigoulet M., Aguilaniu H., Avéret N., Bunoust O., Camougrand N., Grandier-Vazeille X., Larsson C., Pahlman I.L., Manon S., Gustafsson L. (2004). Organization and regulation of the cytosolic NADH metabolism in the yeast Saccharomyces cerevisiae. Mol Cell Biochem. 256-257 (1-2): 73-81.

Rizzuto R., De Stefani D., Raffaello A., Mammucari C. (2012). Mitochondria as sensors and regulators of calcium signalling. Nat Rev Mol Cell Biol. 13 (9): 566-578.

Rostovtseva T., Colombini M. (1997). VDAC channels mediate and gate the flow of ATP: Implications for the regulation of mitochondrial function. Biophys J. 72 (5): 1954-1962.

Rostovtseva T.K., Komarov A., Bezrukov S.M., Colombini M. (2002). Dynamics of nucleotides in VDAC channels: Structure-specific noise generation. Biophys J. 82 (1 Pt 1): 193-205.

Rostovtseva T.K., Bezrukov S.M. (2012). VDAC inhibition by tubulin and its physiological implications. Biochim Biophys Acta. 1818 (6): 1526-1535.

Rostovtseva T.K., Gurnev P.A., Protchenko O., Hoogerheide D.P., Yap T.L., Philpott C.C., Lee J.C., Bezrukov S.M. (2015). $\alpha$-Synuclein shows high affinity interaction with voltage-dependent anion channel, suggesting mechanisms of mitochondrial regulation and toxicity in Parkinson disease. J Biol Chem. 290 (30): 18467-18477.

Rostovtseva, T.K., Hoogerheide D.P., Rovni A., Bezrukov S.M. (2017). Lipids in regulation of the mitochondrial outer membrane permeability, bioenergetics, and metabolism. In: T.K. Rostovtseva (Ed.), Molecular Basis for Mitochondrial Signaling, Springer International Publishing, New York, Chapter. 8: 185-215.

Saks V., Guzun R., Timohhina N., Tepp K., Varikmaa M., Monge C., Beraud N., Kaambre T., Kuznetsov A., Kadaja L., Eimre M., Seppet E. (2010). Structure-function relationships in feedback regulation of energy fluxes in vivo in health and disease: Mitochondrial interactosome. Biochim Biophys Acta. 1797 (6-7): 678-697.

Sen U., Shenoy P.S., Bose B. (2017). Opposing effects of low versus high concentrations of water-soluble vitamins/ dietary ingredients vitamin $\mathrm{C}$ and niacin on colon cancer stem cells (CSCs). Cell Biol Int. 41 (10): 1127-1145.

Shoshan-Barmatz V., Ben-Hail D., Admoni L., Krelin Y., Tripathi S.S. (2015). The mitochondrial voltage-dependent anion channel 1 in tumor cells. Biochim Biophys Acta. 1848 (10 PtB): 2547-2575.

Shoshan-Barmatz V., Krelin Y., Shteinfer-Kuzmine A., Arif T. (2017). Voltage-dependent anion channel 1 as an emerging drug target for novel anti-cancer therapeutics. Front Oncol. 7: 154 .

Shoshan-Barmatz V., Krelin Y., Shteinfer-Kuzmine A. (2018). VDAC1 functions in $\mathrm{Ca}^{2+}$ homeostasis and cell life and death in health and disease. Cell Calcium. 69: 81-100.

Simson P., Jepihhina N., Laasmaa M., Peterson P., Birkedal R., Vendelin M. (2016). Restricted ADP movement in cardiomyocytes: Cytosolic diffusion obstacles are complemented with a small number of open mitochondrial voltagedependent anion channels. J Mol Cell Cardiol. 97: 197-203.

Timohhina N., Guzun R., Tepp K., Monge C., Varikmaa M., Vija H., Sikk P., Kaambre T., Sackett D., Saks V. (2009). Direct measurement of energy fluxes from mitochondria into cytoplasm in permeabilized cardiac cells in situ: Some evidence for mitochondrial interactosome. J Bioenerg Biomembr. 41: 259-275.

Vander Heiden M.G., Chandel N.S., Li X.X., Schumacker P.T., Colombini M., Thompson C.B. (2000). Outer mitochondrial membrane permeability can regulate coupled respiration and cell survival. Proc Natl Acad Sci USA. 97 (9): 4666-4671.

Vazeille X., Larsson C., Pahlman I.L., Manon S., Gustafsson L. (2004) Organization and regulation of the cytosolic NADH metabolism in the yeast Saccharomyces cerevisiae. Mol Cell Biochem. 256-257 (1-2): 73-81.

Wallimann T., Tokarska-Schlattner M., Schlattner U. (2011). The creatine kinase system and pleiotropic effects of creatine. Amino Acids. 40: 1271-1296.

Wilson J.E. (1997). Homologous and heterologous interactions between hexokinase and mitochondrial porin: Evolutionary implications. J Bioenerg Biomembr. 29 (1): 97-102.

Xia J., Xu H., Zhang X., Allamargot C., Coleman K.L., Nessler R., Frech I., Tricot G., Zhan F. (2017). Multiple myeloma tumor cells are selectively killed by pharmacologicallydosed ascorbic acid. EBioMedicine. 18: 41-49.

Zizi M., Forte M., Blachly-Dyson E., Colombini M. (1994) $\mathrm{NADH}$ regulates the gating of VDAC, the mitochondrial outer membrane channel. J Biol Chem. 269 (3): 1614-1616.

Zorova L.D., Popkov V.A., Plotnikov E.Y., Silachev D.N., Pevzner I.B., Jankauskas S.S., Babenko V.A., Zorov S.D., Balakireva A.V., Juhaszova M, Sollott S.J., Zorov D.B. (2017). Mitochondrial membrane potential. Anal Biochem pii. S0003-2697 (17): 30293-2. 